\title{
Measurements of Shielding Effectiveness and Cavity Characteristics of Airplanes
}

David A. Hill

Myron L. Crawford

Robert T. Johnk

Arthur R. Ondrejka

Dennis G. Camell

U.S. DEPARTMENT OF COMMERCE

Technology Administration

National Institute of Standards

and Technology

Electromagnetic Fields Division

Electronics and Electrical Engineering Laboratory

Boulder, Colorado 80303-3328

$-Q C$

100

.056

NLT

NO. 5023

1994 



\section{NISTIR 5023}

\section{Measurements of Shielding Effectiveness and Cavity Characteristics of Airplanes}

\author{
David A. Hill \\ Myron L. Crawford \\ Robert T. Johnk \\ Arthur R. Ondrejka \\ Dennis G. Camell
}

U.S. DEPARTMENT OF COMMERCE

Technology Administration

National Institute of Standards

and Technology

Electromagnetic Fields Division

Electronics and Electrical Engineering Laboratory

Boulder, Colorado 80303-3328

July 1994

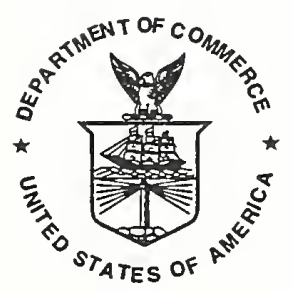

U.S. DEPARTMENT OF COMMERCE Ronald H. Brown, Secretary

TECHNOLOGY ADMINISTRATION

Mary L. Good, Under Secretary for Technology

NATIONAL INSTITUTE OF STANDARDS

AND TECHNOLOGY

Aratl Prabhakar, Dlrector 

CONTENTS

Page

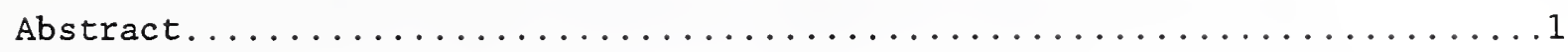

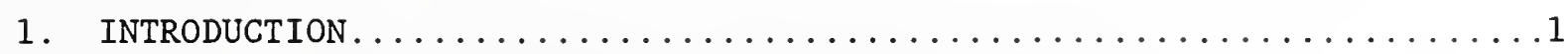

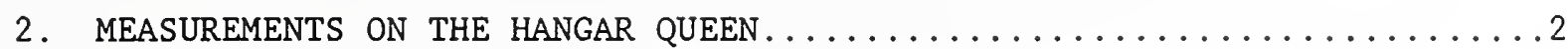

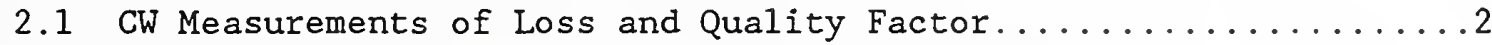

2.2 Time-Domain Measurements of Cavity Time Constant.............5

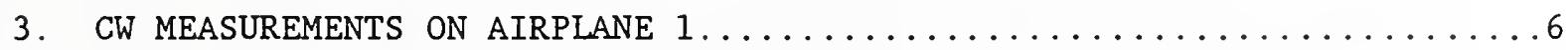

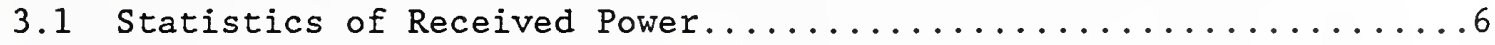

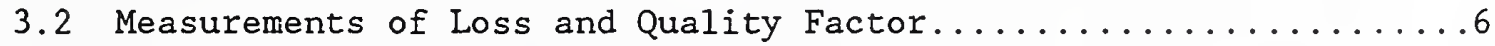

3.3 Measurements of Shielding Effectiveness.................

3.4 Coupling from the Main Cabin to the Avionics Bay..............10

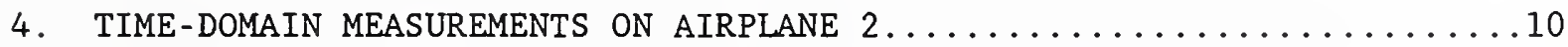

4.1 Measurements of Cavity Time Constant...................... 10

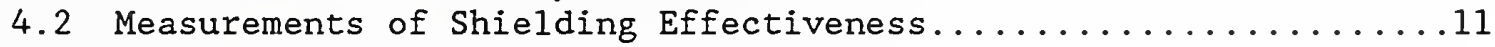

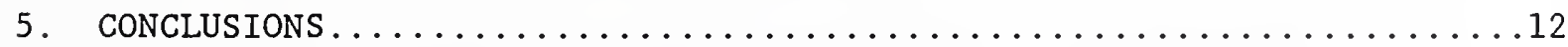

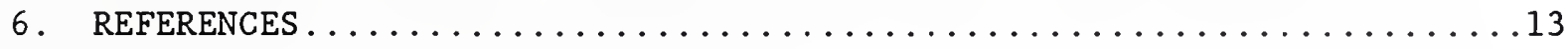




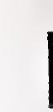


MEASUREMENTS OF SHIELDING EFFECTIVENESS

AND CAVITY CHARACTERISTICS OF AIRPLANES

David A. Hill, Myron L. Crawford, Robert T. Johnk, Arthur R. Ondrejka, and Dennis G. Camell

Electromagnetic Fields Division

National Institute of Standards and Technology

Boulder, Colorado 80303

\begin{abstract}
We present measured data for shielding effectiveness, cavity $Q$, and cavity time constant of three small (twin-engine) airplanes for frequencies from $400 \mathrm{MHz}$ to $18 \mathrm{GHz}$. Both $\mathrm{cw}$ and time-domain measurement methods were used, but the time-domain method yields higher values of cavity $Q$. Both methods yield $Q$ values below a theoretical upper bound determined by window leakage losses. The measured shielding effectiveness is variable, but averages about $15 \mathrm{~dB}$. The measured time constants are also variable and average about 15 ns. This short time constant is a result of the low $Q$ of the aircraft cavities.
\end{abstract}

Key words: airplane; cavity coupling; $\mathrm{cw}$ measurement; mode stirring; quality factor; shielding effectiveness; time constant; time-domain measurement.

\title{
1. INTRODUCTION
}

The possibility of electromagnetic interference (EMI) to aircraft electronics from high intensity radiated fields (HIRFs) has been under study for several years [1]. Because the shielding effectiveness of aircraft skins is not well characterized, the interior fields that excite aircraft electronics are not well characterized even if the incident field is known. The National Institute of Standards and Technology (NIST) has recently developed a theoretical model for the shielding effectiveness (SE), quality factor (Q), and time constant $(\tau)$ of electrically large cavities with apertures and has validated the model with measurements on a loaded rectangular cavity with an aperture [2]. The purpose of this report is to describe the measurement techniques that were used and results that were obtained on three small (twin-engine) airplanes. 
The measurements were made at the Naval Surface Warfare Center (NSWC), Dahlgren, Virginia, over approximately two weeks. Measurements were made on three different airplanes, but problems with weather and airplane availability resulted in different sets of measurements being made on the three airplanes. Two of the airplanes (designated 1 and 2) were twin-engine planes that were fully equipped for flight and are thought to be representative of civilian twin-engine planes currently in use. The third airplane (called the "hangar queen" at NSWC) was similar to airplane 2, but it had been partially stripped for parts. This airplane is less representative of real airplanes in current use, but was used because of its availability. Both $\mathrm{cw}$ and pulse measurement methods were used to obtain shielding effectiveness, quality factor, and time constant.

The organization of this report is as follows. Section 2 covers the measurements on the hangar queen. Both $\mathrm{cw}$ and time-domain methods were used. Section 3 contains the extensive $\mathrm{cw}$ measurement results of $\mathrm{Q}$ and $\mathrm{SE}$ that were obtained on airplane 1. The effectiveness of mechanical stirring is covered in detail. Section 4 contains the time-domain measurement results of $\tau$ and $S E$ that were obtained on airplane 2 . Section 5 contains conclusions and recommendations for further work.

2. MEASUREMENTS ON THE HANGAR QUEEN

The hangar queen is a twin-engine, six-passenger airplane that has been partially stripped for parts by NSWC. This is the only airplane that was available for both $\mathrm{cw}$ and time-domain measurements.

\subsection{CW Measurements of Loss and Quality Factor}

The main cabin of the hangar queen was instrumented with transmitting and receiving antennas and a mechanical stirrer as shown in figure 1. Transmission loss measurements were made for frequencies from $200 \mathrm{MHz}$ to 18 $\mathrm{GHz}$. The cable losses were eliminated by performing a direct-connection, 
reference measurement. The main purpose of the loss measurements was to determine the main cabin $Q$ from the transmission loss [2-4]:

$$
Q=\frac{16 \pi^{2} V}{\lambda^{2}} \frac{P_{r}}{P_{t}},
$$

where $P_{t}$ is the transmitted power, $P_{r}$ is the received power, $\lambda$ is the freespace wavelength, and $V$ is the cavity volume. Equation ( 1 ) is based on the assumption that the cavity fields are well stirred, and $\mathrm{P}_{\mathrm{r}} / \mathrm{P}_{t}$ is the transmission loss averaged over stirrer position.

To demonstrate the effectiveness of the stirrer, we show a plot of the stir ratio (maximum minus minimum received power in $\mathrm{dB}$ ) over the entire frequency range, $200 \mathrm{MHz}$ to $18 \mathrm{GHz}$, in figure 2. There were three people in the main cabin, and their presence adds to the total absorption loss [2]. The stir ratio is variable, but is high enough (on the order of $20 \mathrm{~dB}$ ) to indicate that the stirrer is effective.

Typical plots of received power versus time as the stirrer is rotating are shown in figure 3 for $200 \mathrm{MHz}$ and figure 4 for $1 \mathrm{GHz}$. The periodic nature of the received power is evident in both figures. Average values are obtained by using values over one cycle. The stirrer rotation rate can be varied, and a lower rate is required at higher frequencies where there is more structure to be captured and recorded. The features of sharp nulls and smooth peaks are typical of the interference phenomenon that occurs in modestirred cavities.

The rapid change of received power with frequency is illustrated in figures 5 and 6 . The time waveforms change dramatically with a frequency change of only $0.01 \mathrm{GHz}$ in figure 5 or $0.2 \mathrm{GHz}$ in figure 6 . However, the average value does not change much. The large change in received power with antenna position is illustrated in figure 7 for a frequency of $1.0 \mathrm{GHz}$. Again, the average value of received power does not change much with antenna position. This is consistent with the theoretical and experimental results in [2].

Both maximum and average received power have been used in reverberation chamber [4,5] and cavity [2] measurements. For high-Q chambers, the 
difference is typically on the order of $8 \mathrm{~dB}$, but for low-Q chambers the difference can be less. Figure 8 shows the maximum to average ratio measured in the main cabin of the hanger queen for frequencies from $200 \mathrm{MHz}$ to $18 \mathrm{GHz}$. The ratio is variable, but it is typical of low Q cavities that the ratio is somewhat below $8 \mathrm{~dB}$.

A fairly complete theory for the $Q$ of a lossy cavity was presented and experimentally verified in [2]. We do not have enough information on the walls and the interior of the hangar queen to estimate all the losses, but we do have approximate dimensions of the main cabin and windows. From these dimensions, we have estimated the cabin volume $V=7.25 \mathrm{~m}^{3}$ and the total window area $A=2.61 \mathrm{~m}^{2}$. We can use average measured values of the ratio $\mathrm{P}_{\mathrm{r}} / \mathrm{P}_{t}$ of received to transmitted power to determine $\mathrm{Q}$ from eq (1). A second method for measuring $Q$ is to measure the time constant $\tau$ and to determine $Q$ from [2]

$$
\mathrm{Q}=\omega \tau,
$$

where $\omega$ is the angular frequency. The time constant measurement will be described in the following section. The theoretical value $Q_{3}$ due to leakage (window) loss can be calculated from [2]

$$
\mathrm{Q}_{3}=\frac{8 \pi \mathrm{V}}{\lambda \mathrm{A}},
$$

where we have assumed that the windows are electrically large. We have also neglected any effects of window glass. Figure 9 shows $Q$ measured by the two methods and $Q_{3}$ as calculated from eq (3). Because $Q_{3}$ accounts for only leakage loss, it can be considered a loose upper bound. It is typical that $Q$ measured by the time constant method is higher than $Q$ measured by transmission loss because the time constant is not affected by antenna mismatch loss [2]. The two methods employed different antenna types (TEM horns for the time-domain method and log-periodic dipoles below $1 \mathrm{GHz}$ and ridged horns above $1 \mathrm{GHz}$ for the $\mathrm{cw}$ method), and that would also introduce some difference in the $Q$ values. For example, ridged horns were found to be 
fairly lossy in previous model measurements [2], and this additional loss lowers the measured $Q$.

\subsection{Time-Domain Measurements of Cavity Time Constant}

The main cabin of the hangar queen was instrumented with transmitting and receiving antennas (TEM horns) and a mechanical stirrer as shown in figure 10. A short pulse was transmitted, and a received waveform was recorded for a number of stirrer positions. Received power was averaged over stirrer positions and Fourier analyzed over time windows. The decay of frequency components from time window to time window was found to follow the expected exponential decay curve. The results for time constant $\tau$ as a function of frequency are shown in table 1 . These are the same time constant values that were used to determine the three $Q$ values in figure 9. The upper frequency limit of $2 \mathrm{GHz}$ is determined by the spectrum of the transmitted pulse.

We can also calculate a theoretical time constant $\tau_{3}$ from the calculated $Q_{3}$ in eq (3) and the relationship between quality factor and time constant in eq (2):

$$
\tau_{3}=Q_{3} / \omega=\frac{4 V}{c A}
$$

where $c$ is the free-space velocity of light. This time constant $\tau_{3}$ is independent of frequency and can be considered an upper bound because it accounts only for leakage loss. If we substitute the volume $V$ and window area $\mathrm{A}$ for the hangar queen into eq (4), we obtain $\tau_{3}=37.0 \mathrm{~ns}$. This value is about twice the measured values in table 1 . 


\section{CW MEASUREMENTS ON AIRPLANE 1}

Airplane 1 is a twin-engine, six-passenger plane that is fully equipped for flight. From drawings, we estimate that its main cabin volume $\mathrm{V}$ is approximately $9.46 \mathrm{~m}^{3}$ and its window area $\mathrm{A}$ is approximately $2.15 \mathrm{~m}^{2}$. This plane was available only during the time that we were equipped for $\mathrm{cw}$ measurements.

\subsection{Statistics of Received Power}

The main cabin of airplane 1 was instrumented with transmitting and receiving antennas and a mechanical stirrer as shown previously in figure 1. Figure 11 shows the cumulative distribution of the measured received power at a frequency of $1 \mathrm{GHz}$ and an exponential distribution for comparison. The exponential distribution has been shown to be a good fit to power received in a mechanically stirred reverberation chamber $[6,7]$. Since this same distribution is a good fit to the power received in the main cabin of airplane 1, we conclude that a reverberation chamber environment is a good match to the electromagnetic environment found in an airplane cabin. Other frequencies and antenna configurations showed similar agreement with the exponential distribution. Thus it appears that electromagnetic immunity testing in reverberation chambers is a valid test method for electronic equipment to be used in airplanes.

\subsection{Measurements of Loss and Quality Factor}

Transmission loss measurements between two antennas in the main cabin of airplane 1 were made for frequencies from $200 \mathrm{MHz}$ to $18 \mathrm{GHz}$. The average (over stirrer position) and minimum transmission loss are shown in figure 12. The difference between the two curves is shown in figure 13. As with the hangar queen data in figure 8 , the difference tends to be somewhat below the usual $8 \mathrm{~dB}$ measured in reverberation chambers. 
In figure 14 we show the measured $Q$ and the calculated $Q_{3}$ due to window leakage. The measured $Q$ was determined from the average measured transmission loss data in figure 12 and eq (1). The window leakage $\mathrm{Q}_{3}$ was calculated from eq (3) and the estimated values of volume and window area given previously. As with the hangar queen data in figure 9, the measured $Q$ is quite variable, and $Q_{3}$ provides an upper bound.

To illustrate the effectiveness of the stirrer, we show the time variation of the received power as the stirrer is rotating in figures 15 through 17. The periodic nature of the received power is evident in all three figures, and average values are again obtained by using values over one cycle. The waveform variations become more rapid as the frequency is increased. The effect of the orientation (polarization) of the receiving antenna is shown in figure 18 for a frequency of $1 \mathrm{GHz}$.

\subsection{Measurements of Shielding Effectiveness}

For SE measurements, we located the transmitting antenna approximately $15 \mathrm{~m}$ from the center of the airplane and kept a stirrer (tuner) and a receiving antenna inside the aircraft main cabin (test cavity). A block diagram of the test setup is shown in figure 19.

To illustrate the effectiveness of stirring for an external source, we show the time variation of received power as the stirrer is turning in figures 20 through 24. Both the transmitting and receiving antennas are horizontally polarized, and the incidence is nose-on. As the frequency increases, the stirring appears to be less effective (the difference between maximum and minimum decreases). Also, the waveforms are not exactly periodic at the higher frequencies. It may be that the spectrum analyzer is not able to follow the rapid variations and that the stirrer should be rotated more slowly (or stopped at discrete steps). This issue requires further investigation.

Figure 25 shows the time (stirring) variation for a vertically polarized transmitting antenna and a horizontally polarized receiving 
antenna at $0.5 \mathrm{GHz}$. The incidence is nose-on. The periodic nature of the received power is evident for this case.

Figures 26 through 29 show the time (stirring) variation for a horizontally polarized transmitting antenna and a vertically polarized receiving antenna for nose-on incidence. The $18 \mathrm{GHz}$ data in figure 29 do not show exact periodicity and may have been distorted from the response time of the spectrum analyzer.

Figure 30 shows the time (stirring) variation for both transmitting antennas vertically polarized for nose-on incidence and a frequency of $1 \mathrm{GHz}$. The periodicity is evident and the stirring is effective.

In figures 31 through 33 we show the effect of the number of people in the main cabin on the time variation of the received power. Both the transmitting and receiving antennas are horizontally polarized, and the incidence is from the right side of the airplane. As the number of people is increased, the stirring becomes less effective because of the lowering of the cavity $Q$.

Figure 34 shows the ambient received power for frequencies from 200 to $1000 \mathrm{MHz}$ and the received power when the external antenna transmits $10 \mathrm{dBm}$. The transmitting antenna is horizontally polarized, and the receiving antenna is vertically polarized. The incidence is from the tail of the airplane. The ambient field is well below the transmitted field and should not affect the measurements. The same is true of higher frequencies and other measurement configurations.

For SE measurements a reference field measurement is required in the absence of the airplane. Figures 35 and 36 show the reference power received below and above $1 \mathrm{GHz}$. The transmitting antenna is a horizontally polarized $\mathrm{log}$ periodic dipole below $1 \mathrm{GHz}$ or a horizontally polarized ridged horn above $1 \mathrm{GHz}$. Both the transmitting and receiving antennas are located at a height of $2 \mathrm{~m}$, and the horizontal separation is $15 \mathrm{~m}$. The path difference $\Delta \mathrm{r}$ between the direct and ground-reflected rays is $0.524 \mathrm{~m}$. Because the reflection coefficient is approximately a negative real number, interference nulls occur at frequencies where $\Delta r$ is an integer number of wavelengths. This occurs at the following frequencies $f_{n}$ : 


$$
\begin{aligned}
\mathrm{f}_{\mathrm{n}} & =\frac{\mathrm{nc}}{\Delta \mathrm{r}}=\mathrm{n}(0.572 \mathrm{GHz}) \\
& =0.572 \mathrm{GHz}, 1.144 \mathrm{GHz}, 1.716 \mathrm{GHz}, 2.288 \mathrm{GHz}, 2.86 \mathrm{GHz}, \ldots
\end{aligned}
$$

The first null is apparent in figure 35, and the higher frequency nulls are apparent in figure 36. The presence of these nulls in ground-based aircraft measurements has been discussed by Dosch [8]. The cross-polarized (vertically polarized receiving antenna) result in figure 36 is at a reduced level and does not have a regular pattern. The discontinuity at $6 \mathrm{GHz}$ in figure 36 is due to a change in the transmitted power and does not affect the SE results.

The simplest way to define $\mathrm{SE}$ for this experiment is to take the $\mathrm{dB}$ difference between the maximum power received in the main cabin and the reference power in the absence of the aircraft. This is not quite the same as the average power density ratio used in [2], but the numerical results are similar. The gain of the receiving antenna for the reference power measurement is not accurately known, but is probably in the range of 5 to $10 \mathrm{~dB}$. The maximum-to-average ratio for the power density inside the main cabin is also in the 5 to $10 \mathrm{~dB}$ range. These two factors approximately cancel each other when we take the difference in decibels between the maximum received power in the main cabin and the reference received power in the absence of the airplane. However, in future measurements it would probably be better to measure the incident and interior power densities in a way that the results would be independent of the gain of the receiving antenna. Figures 37 and 38 show SE from 0.2 to $18 \mathrm{GHz}$ for two different orientations of the receiving antenna inside the main cabin. Six different incidence directions are shown in each figure. The tail direction has greater SE because the windows are shadowed, but the other incidence directions all give similar results. The convention on the sign of SE is that negative numbers represent shielding where the interior power density is less than the incident power density. The dips in SE correspond to the nulls in the incident field as given by eq (5) and are not representative of higher fields in the interior. These nulls in the reference field are a problem in defining SE because the large aircraft does not see a null over 
its entire surface. This difficulty requires further attention for future SE measurements of airplanes located on the ground.

\subsection{Coupling from the Main Cabin to the Avionics Bay}

Since the main cabin has fairly low SE (about $20 \mathrm{~dB}$ ), coupling from the main cabin to the avionics bay could be important for equipment located in the avionics bay. To study the coupling, we instrumented the main cabin with a transmitting antenna and a stirrer and the avionics bay with a receiving antenna and a stirrer. Otherwise the instrumentation was as shown in figure 1. The stirring effectiveness in the avionics bay is indicated by the stir ratio shown in figure 39. The maximum to average stir ratio is shown in figure 40, and it is somewhat lower than the typical $8 \mathrm{~dB}$.

In figure 41, we show both the average (over stirrer position) and maximum coupling (minimum loss) between the transmitting antenna (located in the main cabin) and the receiving antenna (located in the avionics bay). This level of coupling could be important in some applications, and the mechanism of coupling (wiring, apertures, etc.) is worthy of further study.

\section{TIME-DOMAIN MEASUREMENTS ON AIRPLANE 2}

Airplane 2 is a twin-engine, six-passenger plane that is fully equiped for flight. Its dimensions are the same as those of the hangar queen, so we estimate its volume $V=7.25 \mathrm{~m}^{3}$ and its window area $A=2.61 \mathrm{~m}^{2}$. This plane was available only during the time that we were equipped for timedomain measurements.

\subsection{Measurements of Cavity Time Constant}

The main cabin of airplane 2 was instrumented with transmitting and receiving antennas (TEM horns) and a mechanical stirrer as shown in figure 10. The same pulse method that was described in Section 2.2 was used to 
determine the time constant. The results for the time constant $r$ as function of frequency are shown in table 2 for either two people or four people in the main cabin. We would expect a smaller time constant for four people in the cavity because the losses are higher. Table 2 confirms this except for the highest frequency of $2 \mathrm{GHz}$. The time constants in table 2 could be used to calculate $Q$ from eq (2).

The same upper-bound time constant $\tau_{3}$ can be computed from eq (4). The result is again $37.0 \mathrm{~ns}$ (independent of frequency), and this value is about twice the measured values. A useful quantity for future studies of airplane interiors would be the averaged absorption cross section for a typical person. This would allow the absorption loss to be included in the theoretical Q calculation [2].

\subsection{Measurements of Shielding Effectiveness}

A block diagram of the test setup for shielding effectiveness measurements is shown in figure 42. The transmitting antenna (TEM horn \#2) was located at a height of $1.78 \mathrm{~m}$ and a horizontal separation of $11.6 \mathrm{~m}$ from the center of the airplane. A receiving antenna (TEM horn \#1) and a stirrer (tuner) were located in the main cabin. The setup for the reference field measurement is shown in figure 43. The two antennas were separated by 11.6 $\mathrm{m}$ and were vertically polarized. For the reference field measurement, the ground-reflected pulse which has a time delay was windowed out. This eliminates the frequency oscillations in the reference field that occured in the $\mathrm{cw}$ measurements as shown in figures 35 and 36 . To account for incoherent addition of the direct and ground-reflected fields inside the plane, the reference power was doubled.

To generate SE data, we Fourier-analyzed the reference signal and the signal received inside the airplane for a number of tuner positions. The power received inside the airplane was averaged and divided by the reference power to obtain SE. Results for incidence at $60^{\circ}$ from the nose are shown in table 3. We show only three frequencies, and these SE results are consistent with the SE results for airplane 1 obtained by $\mathrm{cw}$ measurement 
shown in figures 37 and 38. The data processing for the time-domain method needs to be automated to produce more SE data with less manual effort.

\section{CONCLUSIONS}

We have performed cavity $Q$ measurements on three small (twin-engine) airplanes and SE measurements on two of the three airplanes. Both cw and pulse (time-domain) methods were used, and mechanical stirring was used in all cases. The $Q$ of the hangar queen was measured using both techniques, and the time-domain method gave higher $Q$ values as shown in figure 9 . This is to be expected because the time-domain method is not affected by antenna impedance mismatch [2]. Both methods gave lower values than the theoretical upper-bound $Q$ determined from window leakage loss. The time-domain method which uses the cavity time constant has the advantage that the cavity volume does not have to be estimated, but it requires additional data processing that has yet to be automated.

Extensive $\mathrm{cw}$ measurements of $\mathrm{Q}$ and $\mathrm{SE}$ were made on airplane 1 . The curves of received power vs stirrer position show that mechanical stirring is effective in most cases, but in some cases either a direct path signal or the slow response time of the spectrum analyzer causes stirring to be less effective. The ground-reflected signal was observed to cause frequency oscillations in the reference signal and the resultant SE-vs-frequency curves. The $\mathrm{SE}$ values average about $15 \mathrm{~dB}$, but the oscillations can introduce variations of $\pm 10 \mathrm{~dB}$. Incidence from the tail direction shows much higher values of SE because the windows are shadowed. Frequency oscillations have been noted previously [8] in ground-based measurements, but can be avoided by windowing with time-domain methods. All of our $\mathrm{cw}$ results are based on either average or peak values obtained from mechanical stirring, but the cumulative distribution as shown in figure 11 is also of interest. The shape of the distribution is similar to the analytical distribution that has been shown to fit reverberation chamber data. This implies that reverberation chamber EMI testing is a good simulation for EMI testing of electronic equipment in an airplane. 
Time-domain measurements of time constant and SE were made on airplane 2, which was similar, but not identical, to airplane 1. - The method has some potential advantages (the cavity volume is not needed to determine Q, broadband data is obtained from one pulse measurement, and ground reflection can be windowed out) over cw methods, but we need to automate the data processing to take full advantage of the method. The measured time constants are on the order of $15 \mathrm{~ns}$, and such a low value means that typical radar pulses are long enough that interior fields will have time to build up to their steady-state values. The measured $\mathrm{SE}$ values of about $15 \mathrm{~dB}$ are in fair agreement with the values obtained by $\mathrm{cw}$ measurements.

A number of extensions to this work would be desirable. Measurements of $\mathrm{Q}$ and $\mathrm{SE}$ on larger (commercial) airplanes would be desirable. The use of frequency stirring [9] using band-limited, white Gaussian noise [10] or broadband pulses has been shown to be effective in reverberation chamber measurements and should provide faster, more efficient measurements in aircraft cavities. The importance of cavity-to-cavity coupling needs to be further studied since our measurements on airplane 1 show significant coupling from the main cabin to the avionics bay. The transmission properties of conductively coated window glass and fiberglass airframes should also be measured and analyzed.

This research was supported by the Federal Aviation Administration. We thank Gustav Freyer, Universal systems Incorporated, for providing the cumulative distribution curve in figure 11.

\section{REFERENCES}

[1] Guidance to certification of aircraft electrical/electronic systems for operation in the high intensity radiated fields (HIRF) environment. Society of Automotive Engineers, SAE AE4R Committee Report (July 1991).

[2] Hill, D.A.; Adams, J.W.; Ma, M.T.; Ondrejka, A.R.; Riddle, B.F.; Crawford, M.L.; Johnk, R.T. Aperture excitation of electrically large, lossy cavities. Nat. Inst. Stand. Technol. Tech. Note 1361; 1993. 
[3] Corona, P.; Latmiral, G.; Paolini, E. Performance and analysis of a reverberating enclosure with variable geometry. IEEE Trans. Electromag. Compat., EMC-22: 2-5; 1980.

[4] Crawford, M.L.; Koepke, G.H. Design, evaluation, and use of a reverberation chamber for performing electromagnetic susceptibility/vulnerability measurements. Nat. Bur. Stand. (U.S.) Tech. Note 1092; 1986.

[5] Hill, D.A.; Crawford, M.L.; Kanda, M.; Wu, D.I. Aperture coupling to a coaxial air line: theory and experiment. IEEE Trans. Electromag. Compat., EMC-35; 69-74; 1993.

[6] Kostas, J.G.; Boverie, B. Statistical model for a mode-stirred chamber. IEEE Trans. Electromag. Compat., EMC-33: 366-370; 1991.

[7] Lehman, T.H. A statistical theory of electromagnetic fields in complex cavities. EMP Interaction Note 494; May 1993.

[8] Dosch, M.C. The effect of ground reflections on electric field measurements using a HIRF LLCW test system. IEEE International EMC Symposium: $331-119 ; 1993$.

[9] Hill, D.A. Electronic mode stirring for reverberation chambers. IEEE Trans. Electromag. Compat., to be published.

[10] Loughry, T.A. Frequency stirring: an alternate approach to mechanical mode-stirring for the conduct of electromagnetic susceptibility testing. Phillips Laboratory, PL-TR--91-1036; 1991. 
Table 1. Measured time constant for the main cabin of the hangar queen.

Frequency $(\mathrm{GHz})$

$$
\begin{aligned}
& 0.5 \\
& 1.0 \\
& 1.5 \\
& 2.0
\end{aligned}
$$

$\tau$ (ns)

18.63

19.49

16.35

29.72

Table 2. Measured time constant for the main cabin of airplane 2 .

Frequency $(\mathrm{GHz})$ $\tau$ (ns). 2 people $\tau$ (ns), 4 people

0.5
1.0
1.5
2.0

19.67

22.87

16.25

15.93

12.46

14.42

10.67

17.51

Table 3. Measured shielding effectiveness for the main cabin of airplane 2. Incident field: vertical polarization, $60^{\circ}$ from nose.

$\begin{array}{rr}480 & 13.92 \\ 960 & 13.32 \\ 1440 & 22.17\end{array}$




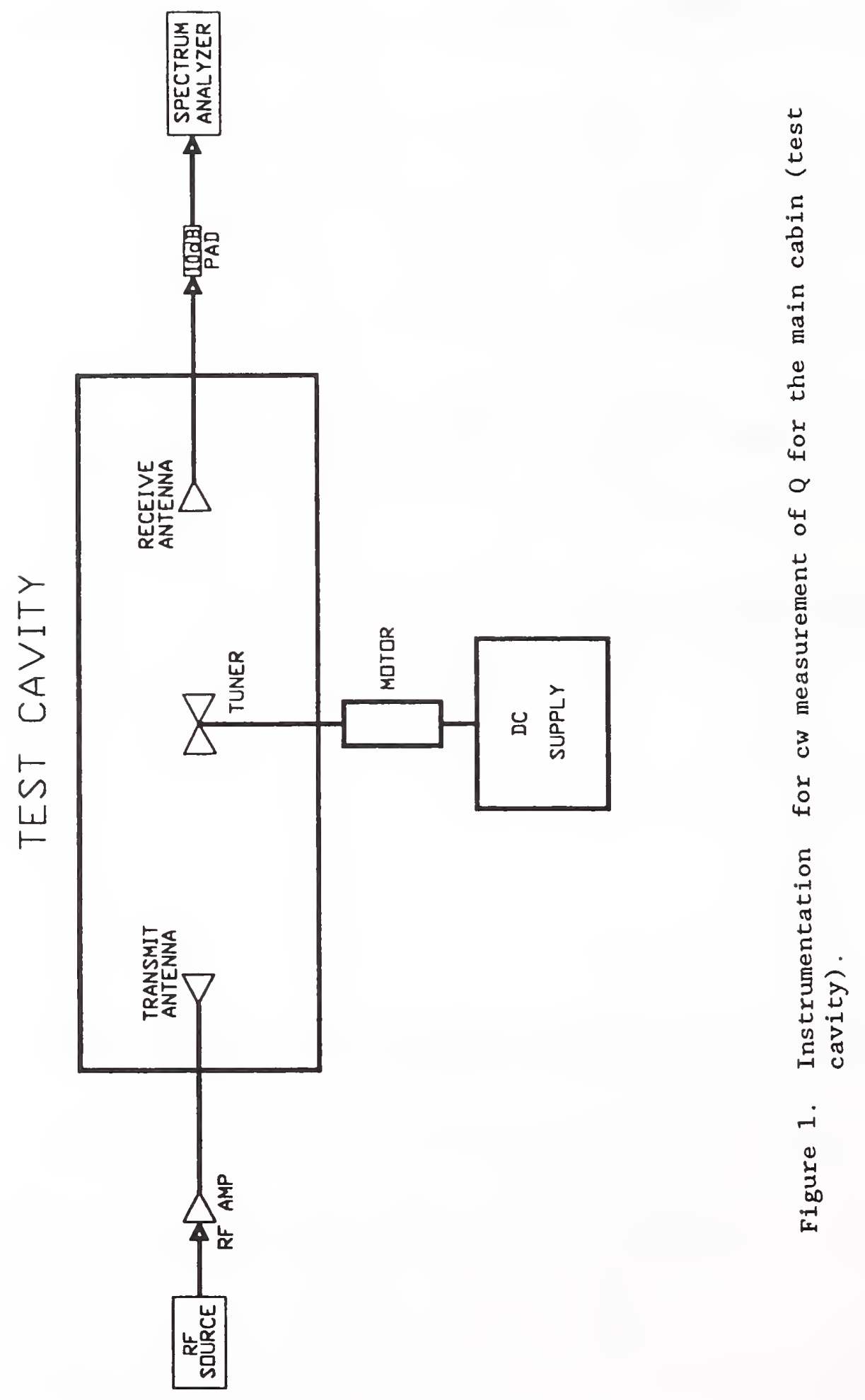




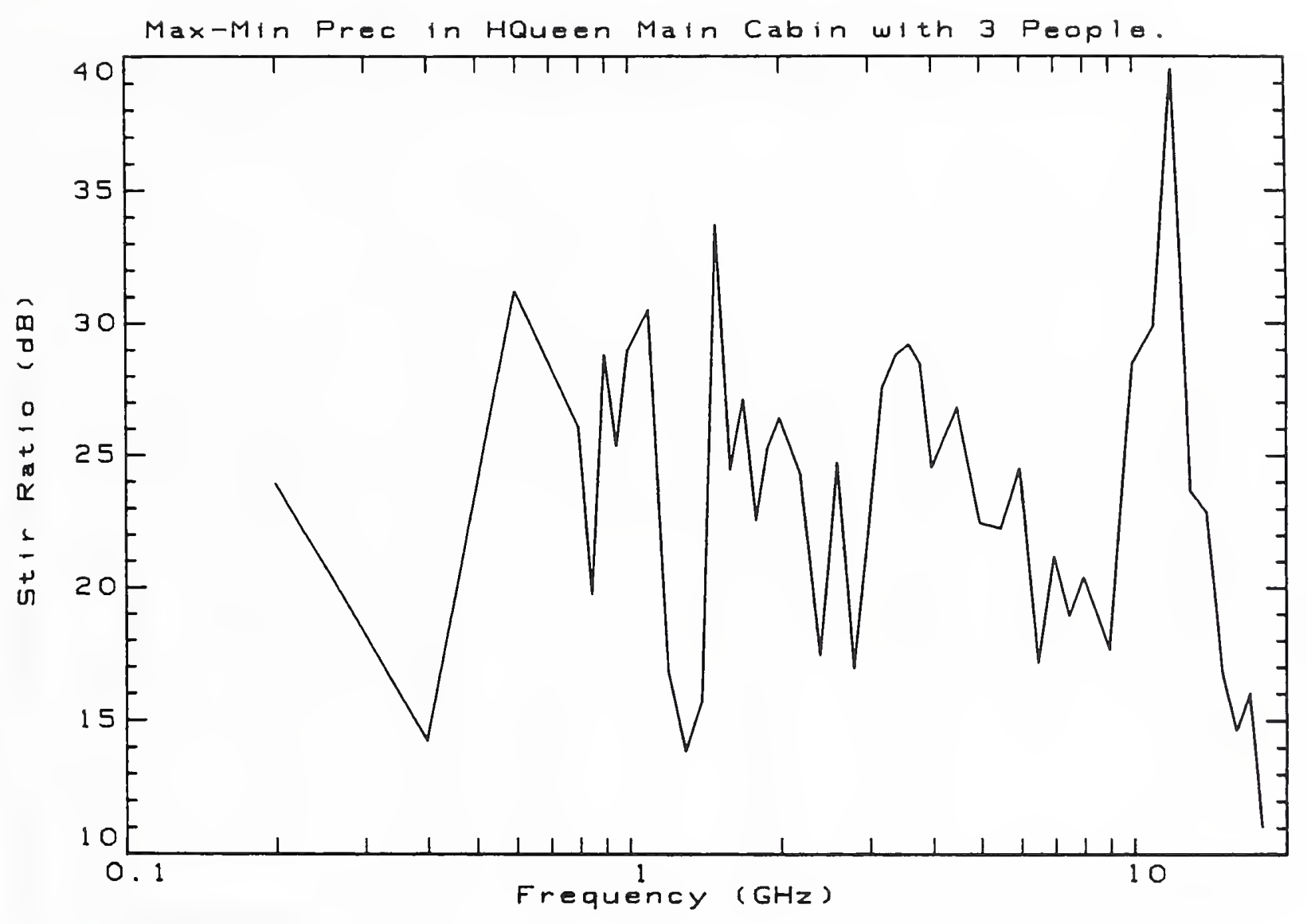

Figure 2. Stir ratio (maximum/minimum) in the main cabin of the hangar queen with three people. 


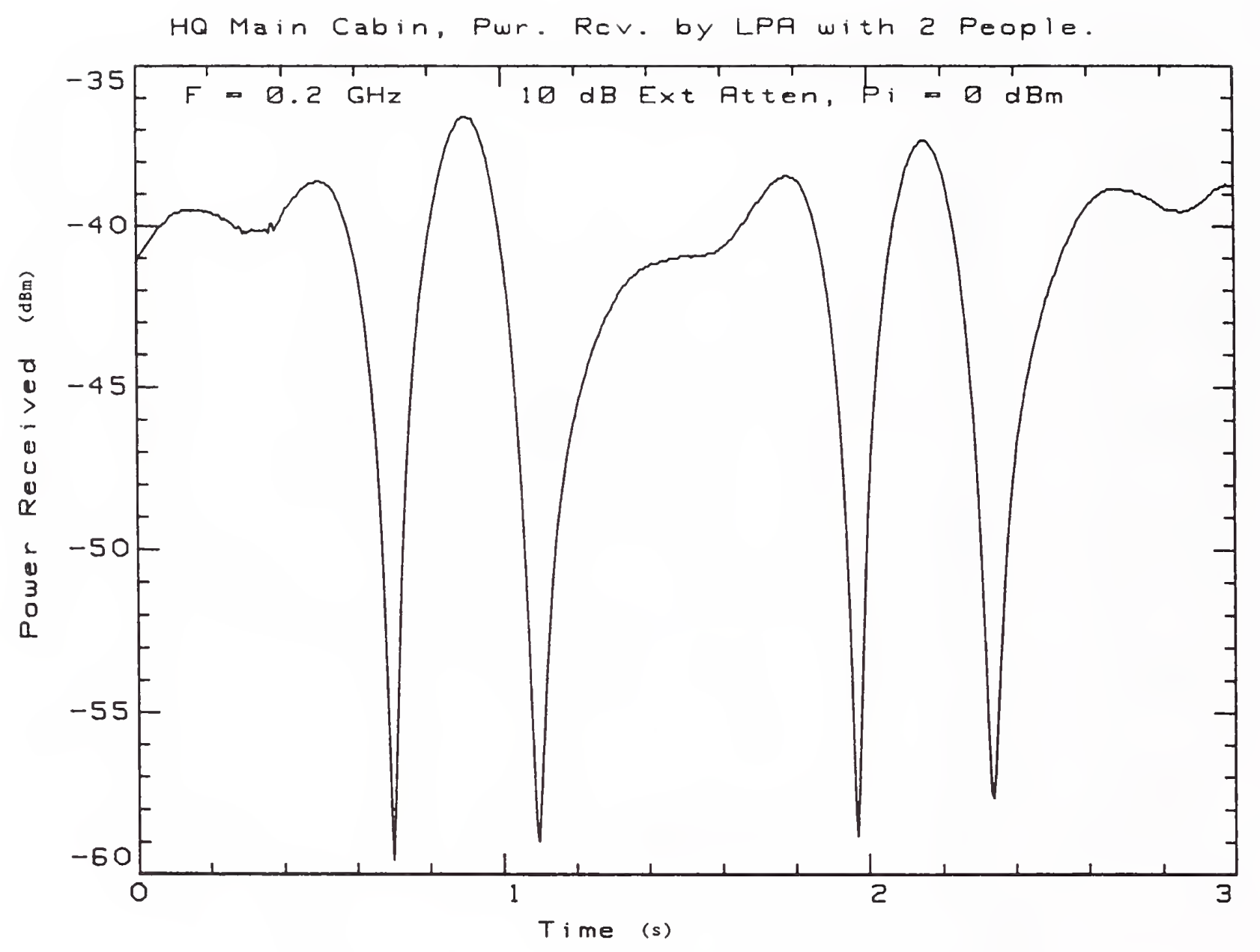

Figure 3. Received power versus time (stirrer position) in the main cabin of the hangar queen with two people. Frequency $=0.2 \mathrm{GHz}$. 


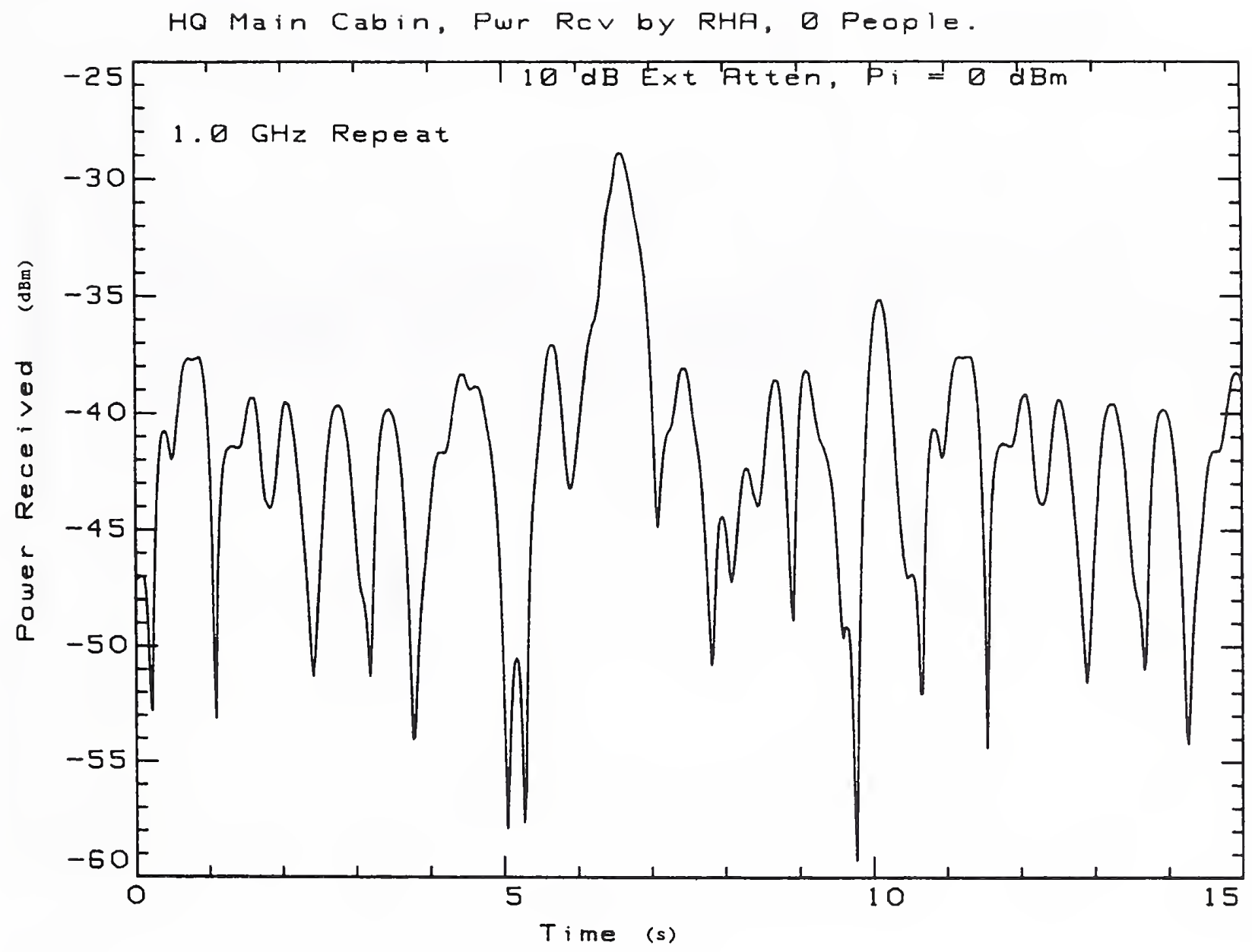

Figure 4. Received power versus time (stirrer position) in the main cabin of the hangar queen with no people. Frequency $=1.0 \mathrm{GHz}$. 


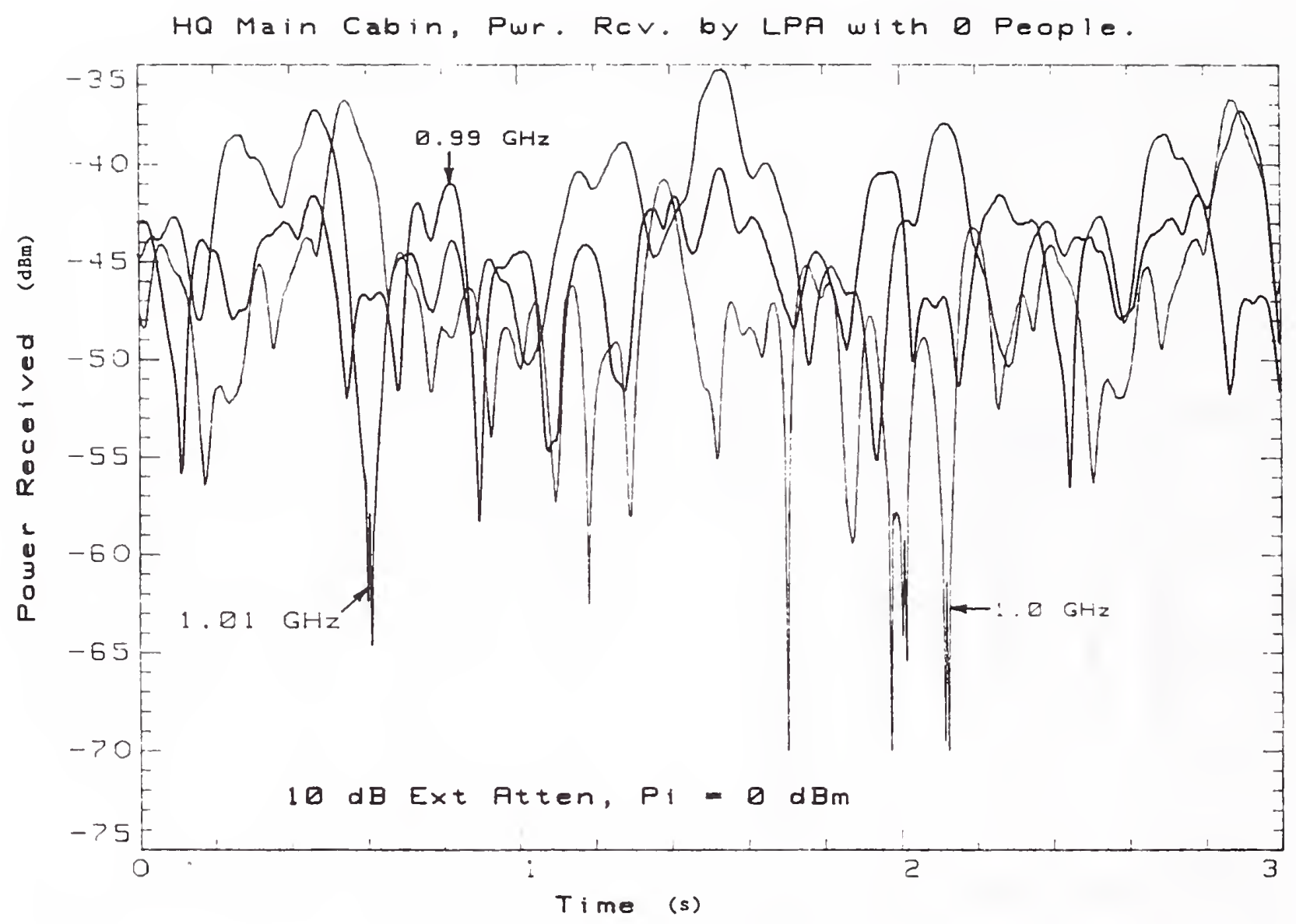

Figure 5. Received power versus time (stirrer position) in the main cabin of the hangar queen with no people. Frequency $=0.99,1.0$, and $1.01 \mathrm{GHz}$. 
HQ Main Cabin, Power Received by RHA, O People.

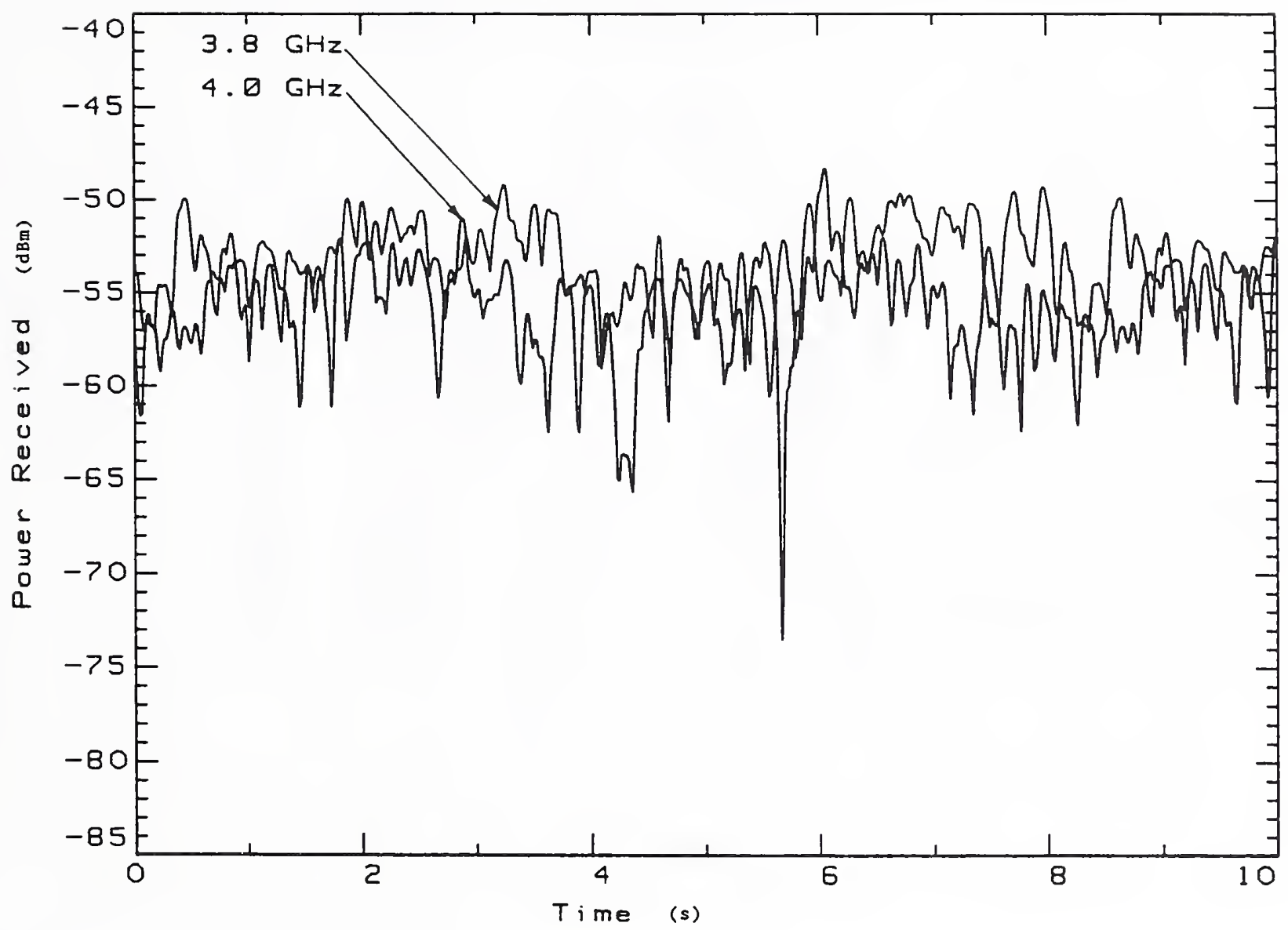

Figure 6. Received power versus time (stirrer position) in the main cabin of the hangar queen with no people. Frequency $=3.8$ and $4.0 \mathrm{GHz}$. 


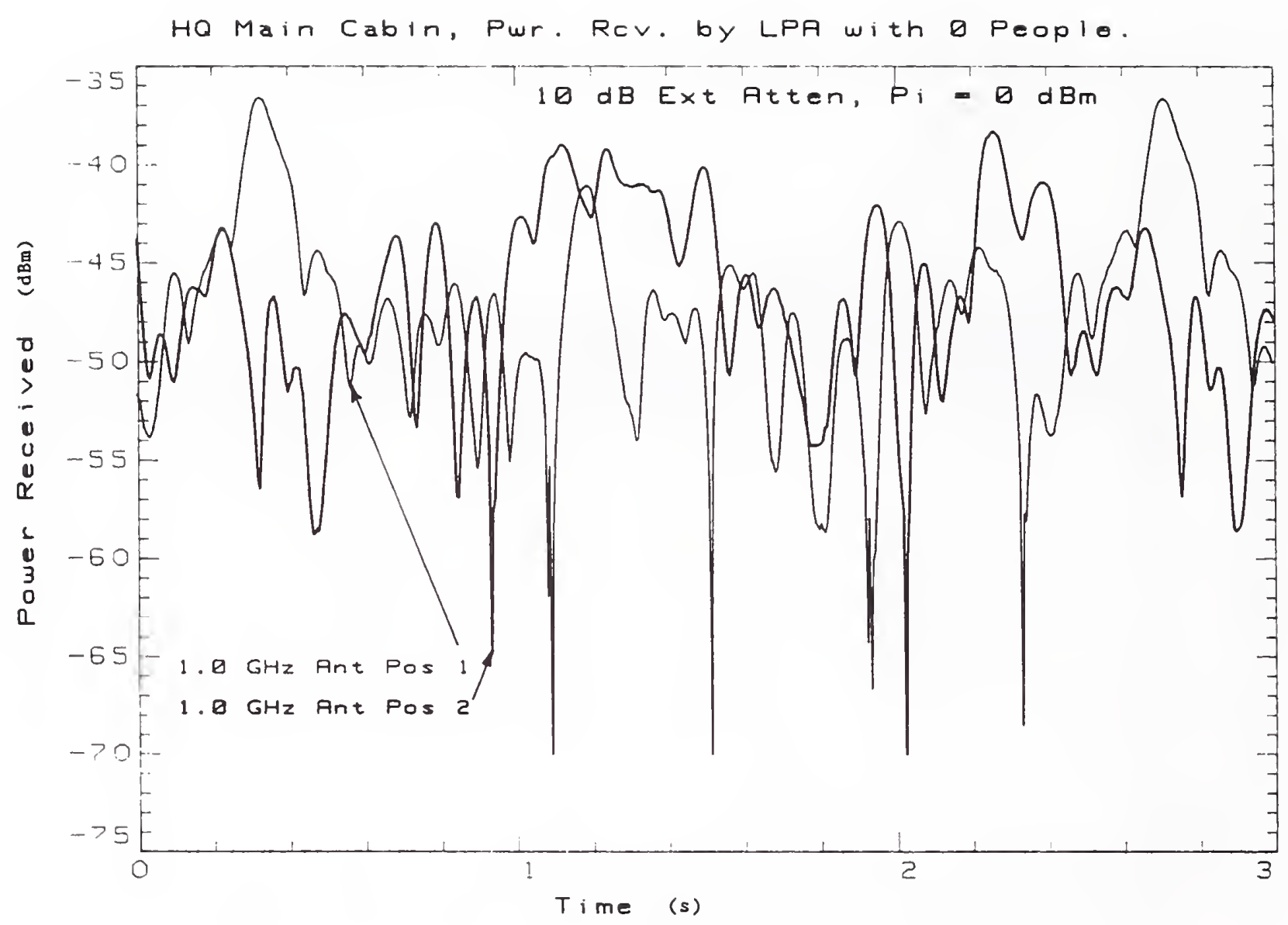

Figure 7. Received power versus time (stirrer position) in the main cabin of the hangar queen with no people for two antenna positions. Frequency $=1.0 \mathrm{GHz}$. 


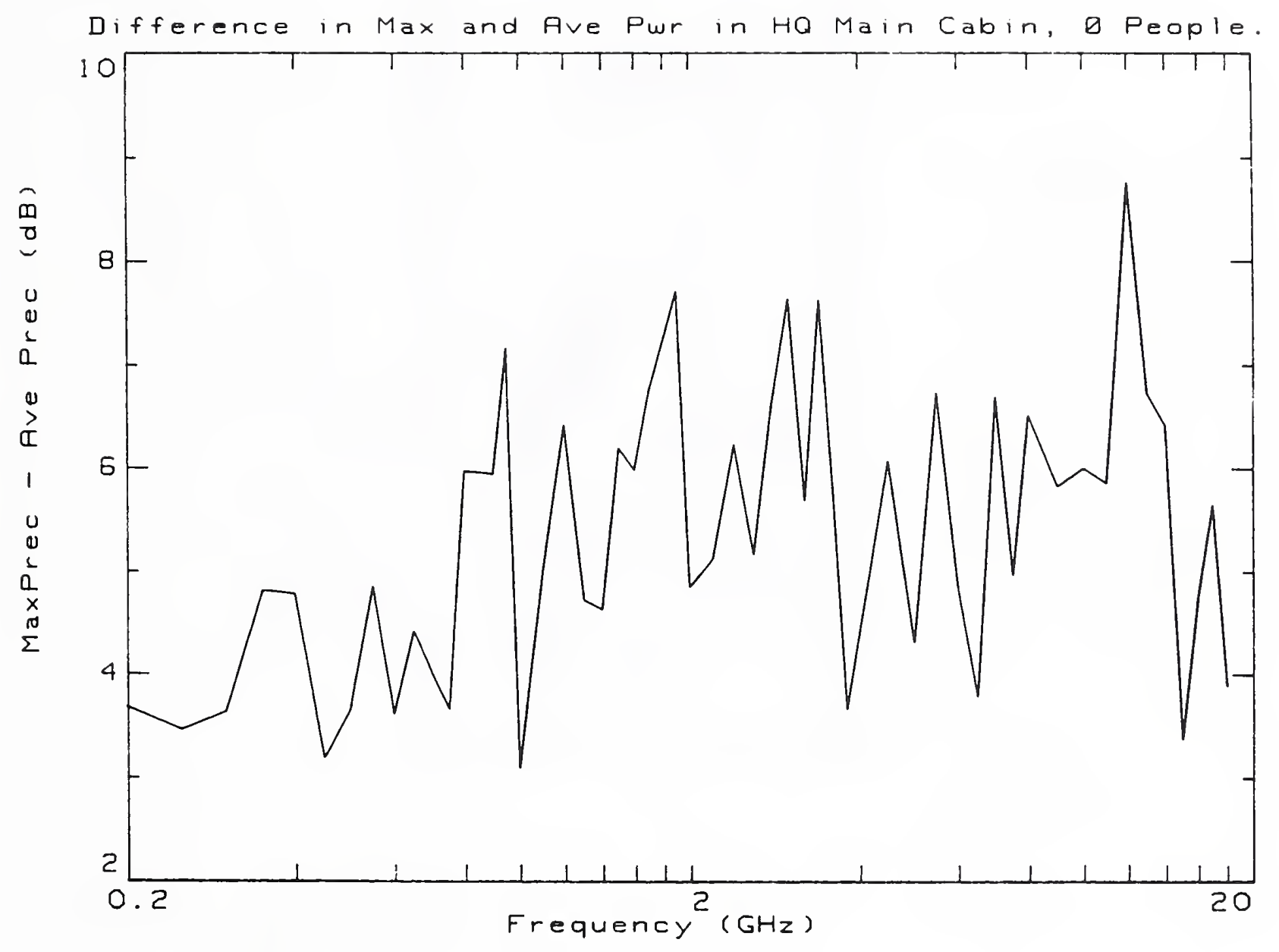

Figure 8. Difference between maximum and average received power in the main cabin of the hangar queen with no people. 


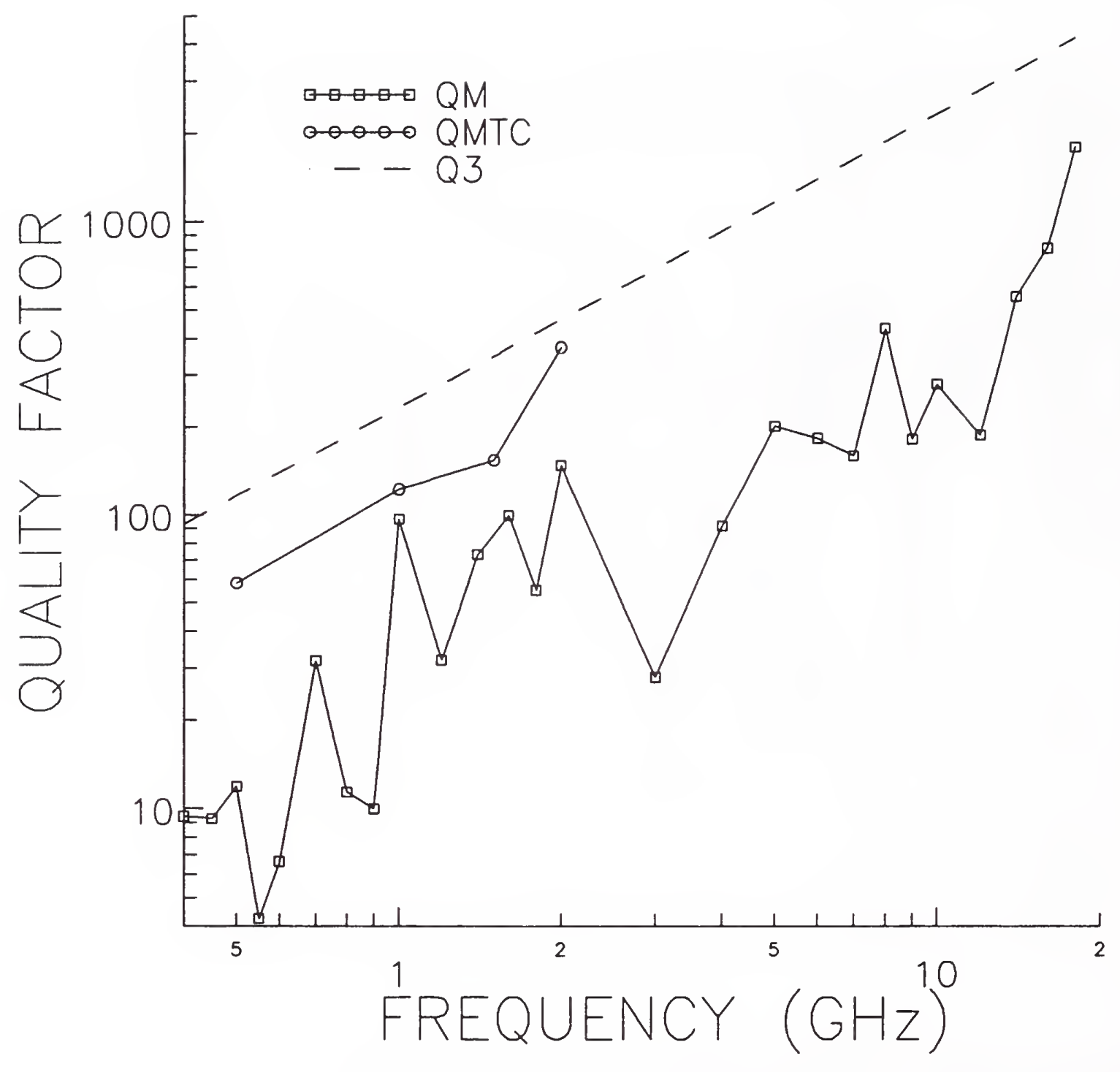

Figure 9. Quality factor of the main cabin of the hangar queen determined by $\mathrm{cw}$ measurement (QM), time-domain measurement (QMTC), and leakage calculation (Q3). 


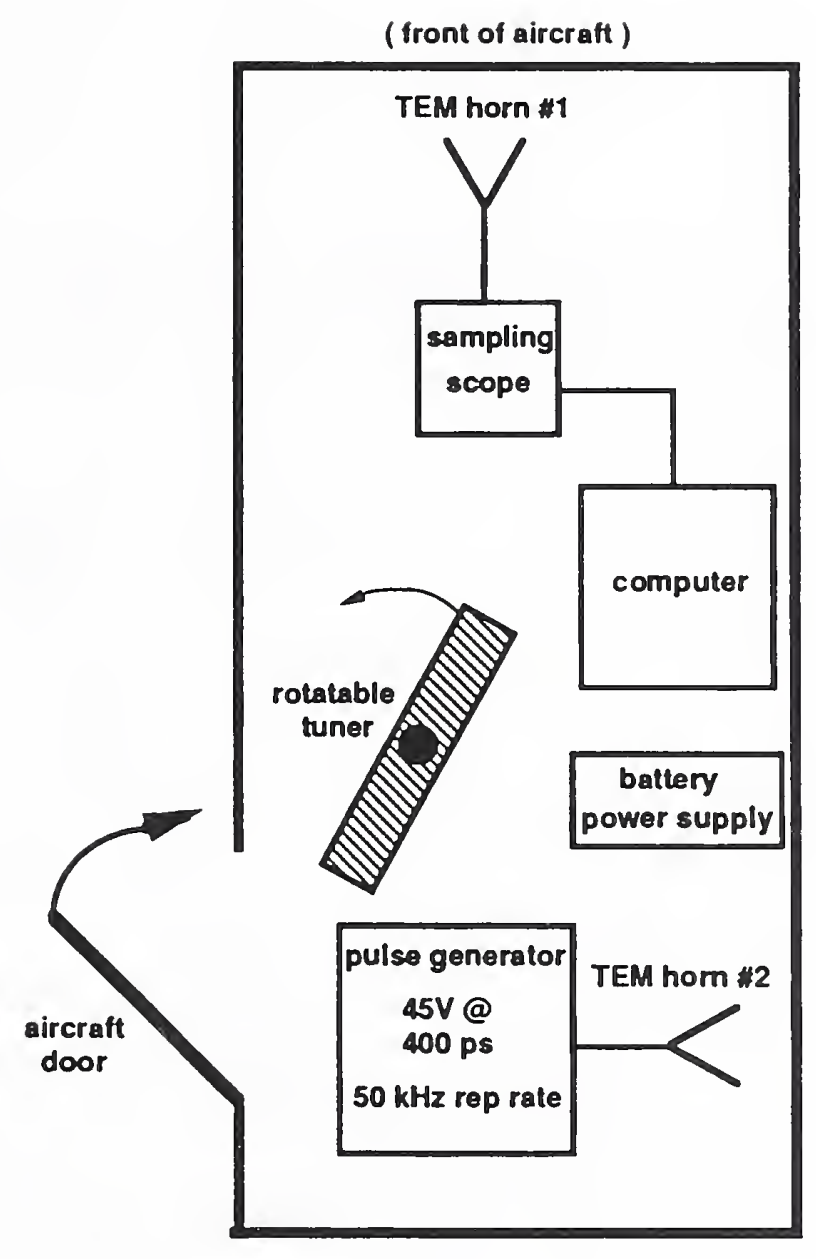

Figure 10. Instrumentation of time-domain measurement of time constant of the main cabin. 
$1 \mathrm{GHz}$

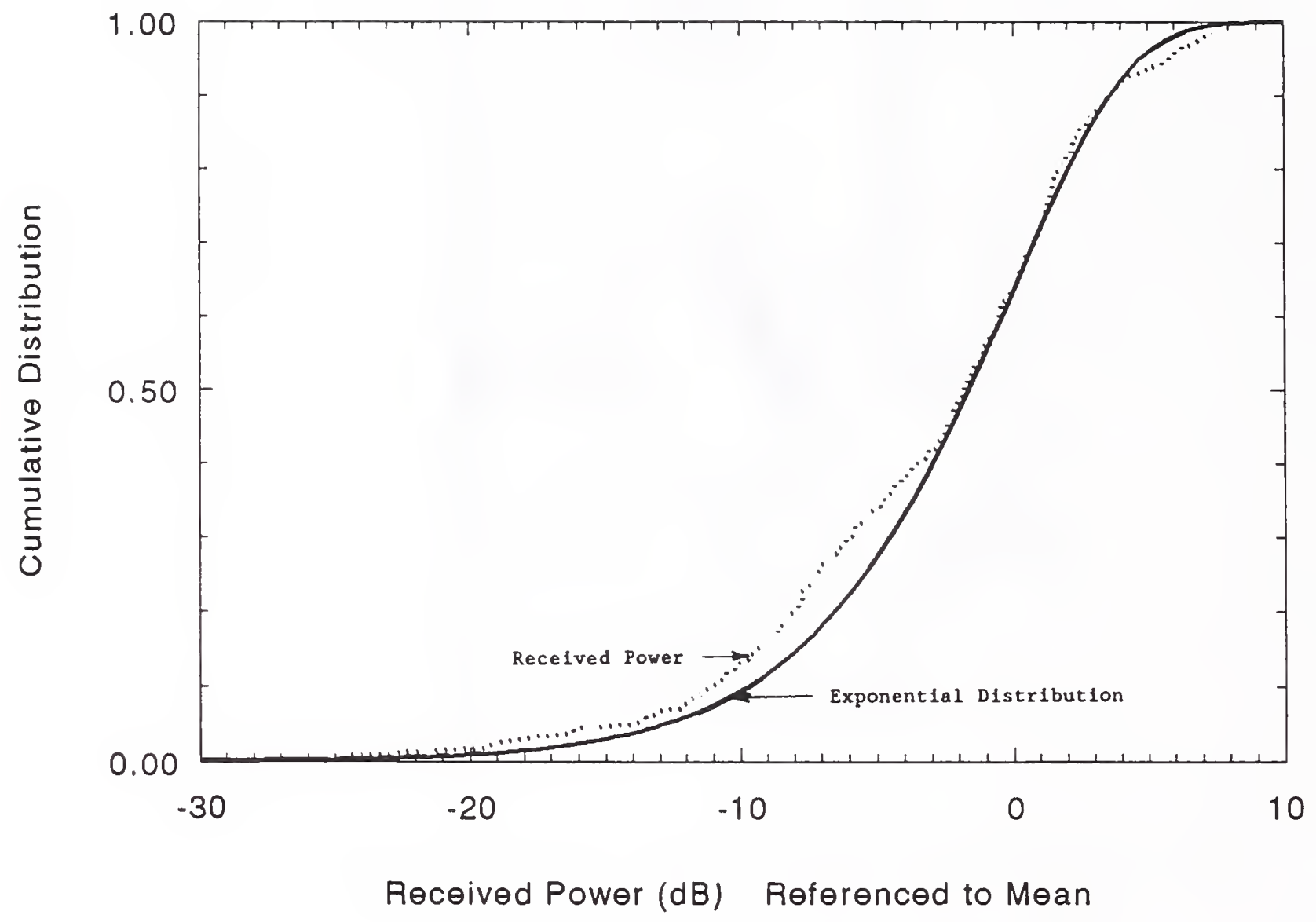

Figure 11. Cumulative distribution of power received in main cabin of airplane 1 at $1.0 \mathrm{GHz}$ and exponential comparison curve. 


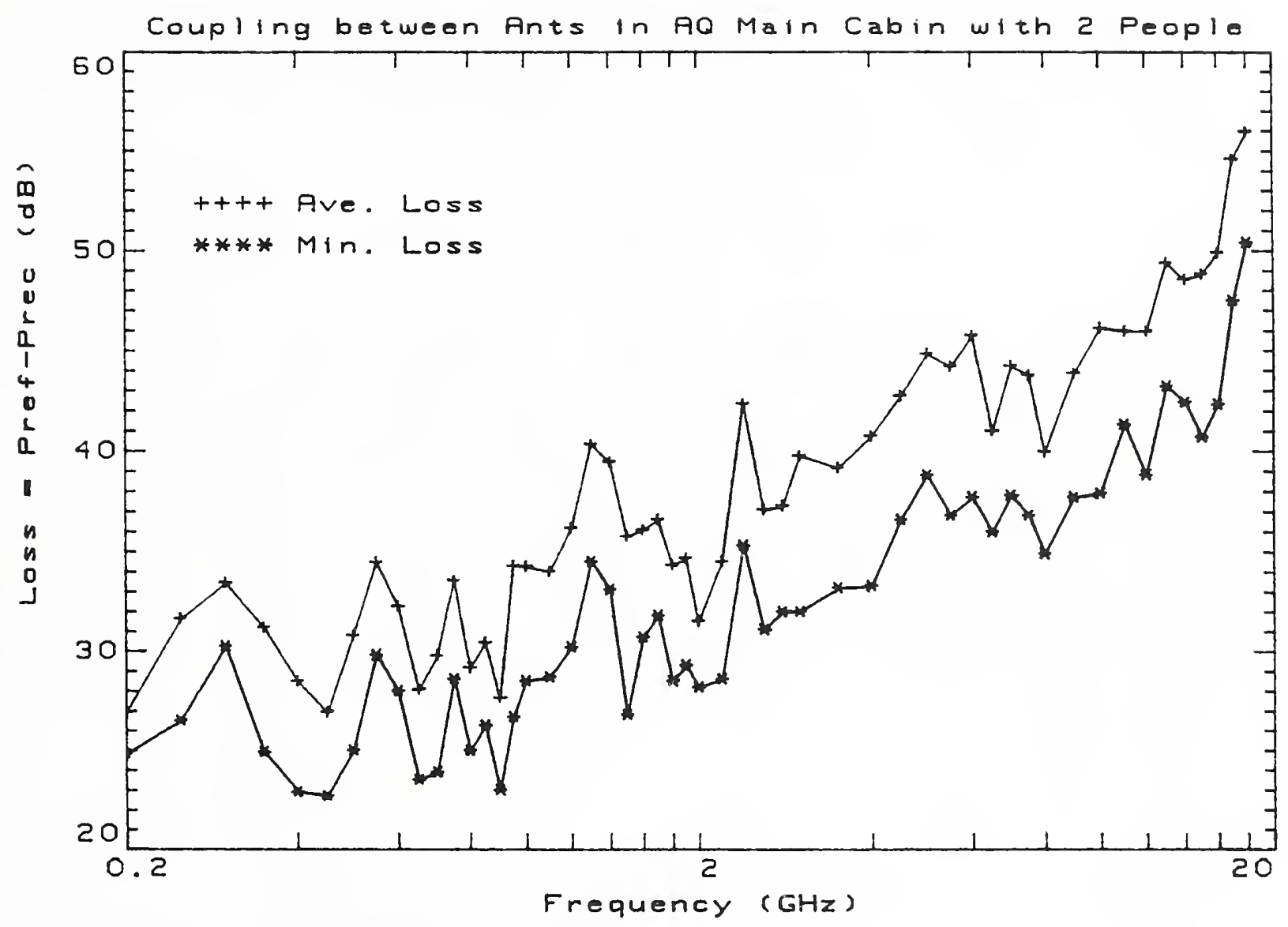

Figure 12. Average and minimum coupling loss between antennas located in the main cabin of airplane 1 with two people. 


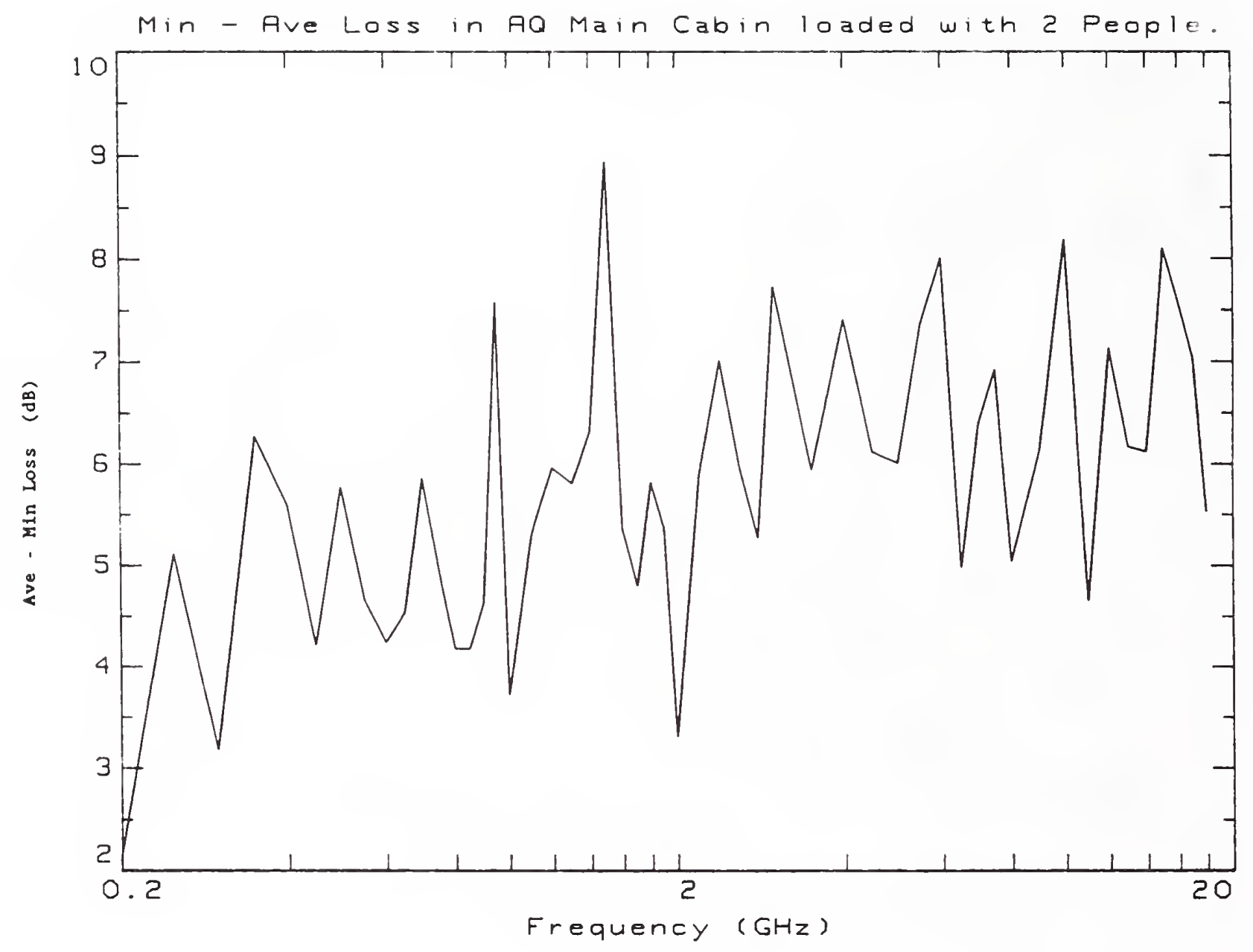

Figure 13. Difference between the minimum and average coupling loss in the main cabin of airplane 1 with two people. 


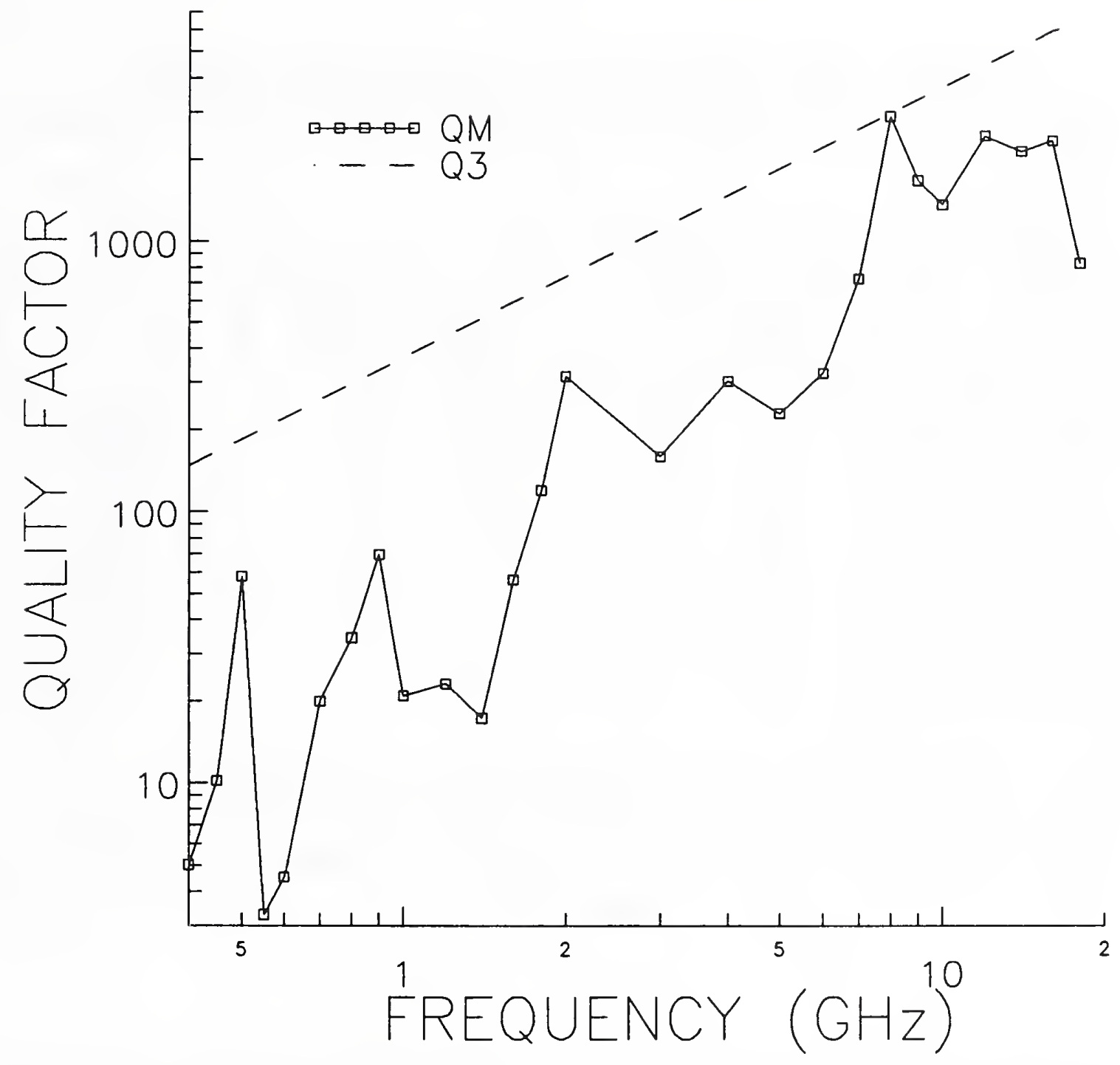

Figure 14. Quality factor of the main cabin of airplane 1 determined by $\mathrm{cw}$ measurement (QM) and leakage calculation (Q3). 


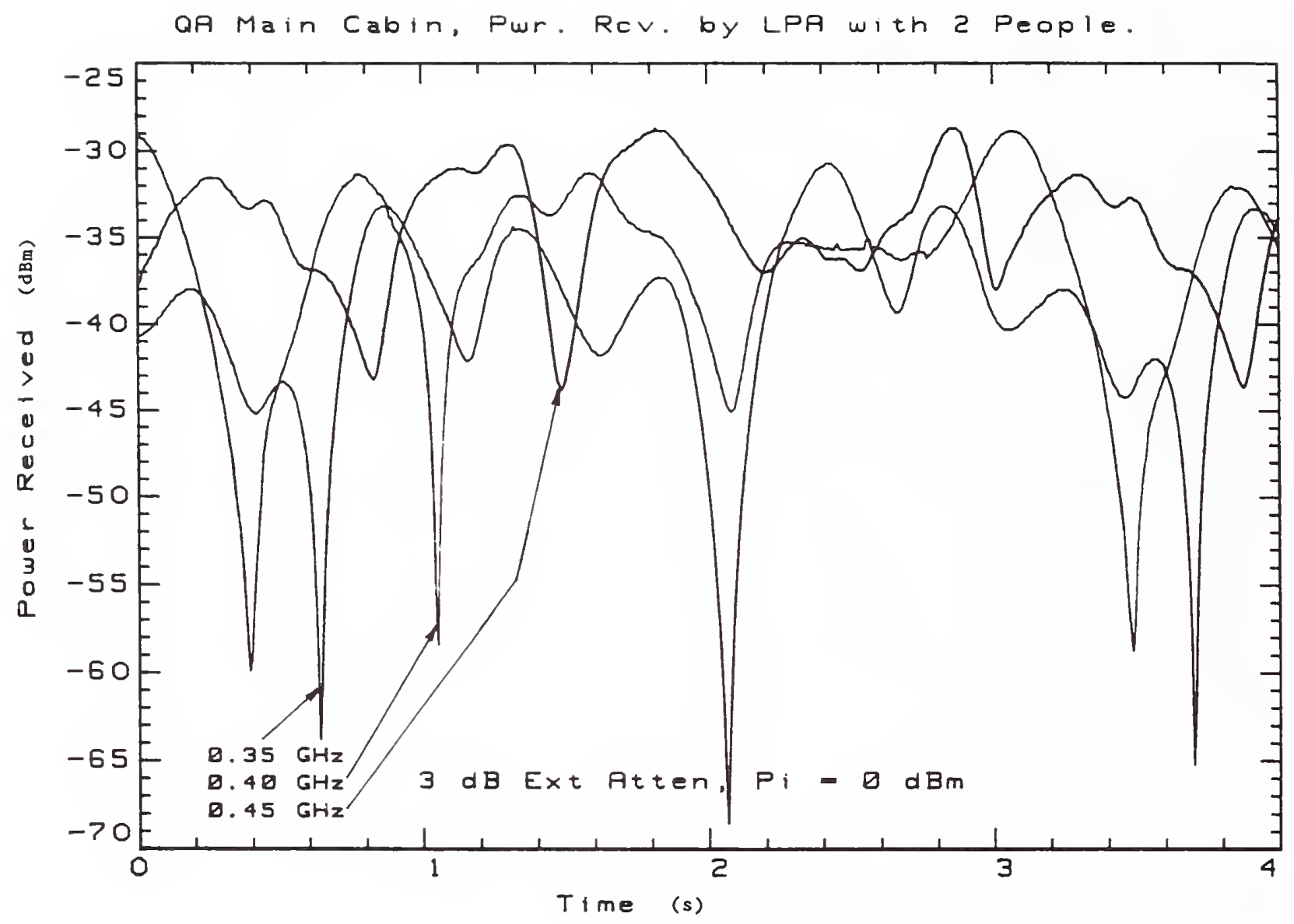

Figure 15. Received power versus time (stirrer position) in the main cabin of airplane 1 for two peoplè. Frequency $=0.35,0.4,0.45 \mathrm{GHz}$. 


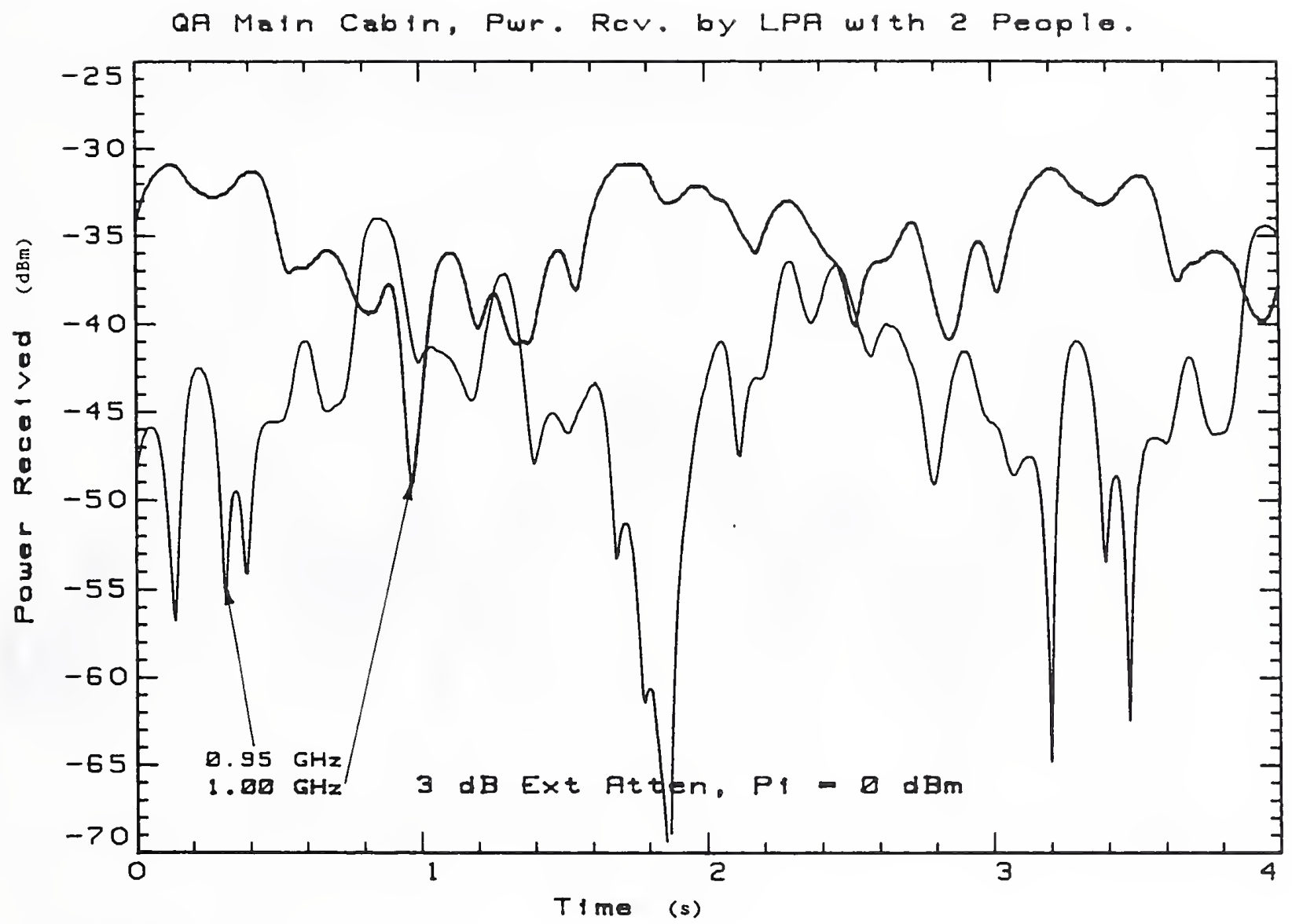

Figure 16. Received power versus time (stirrer position) in the main cabin of airplane 1 for two people. Frequency $=0.95$ and $1.0 \mathrm{GHz}$. 


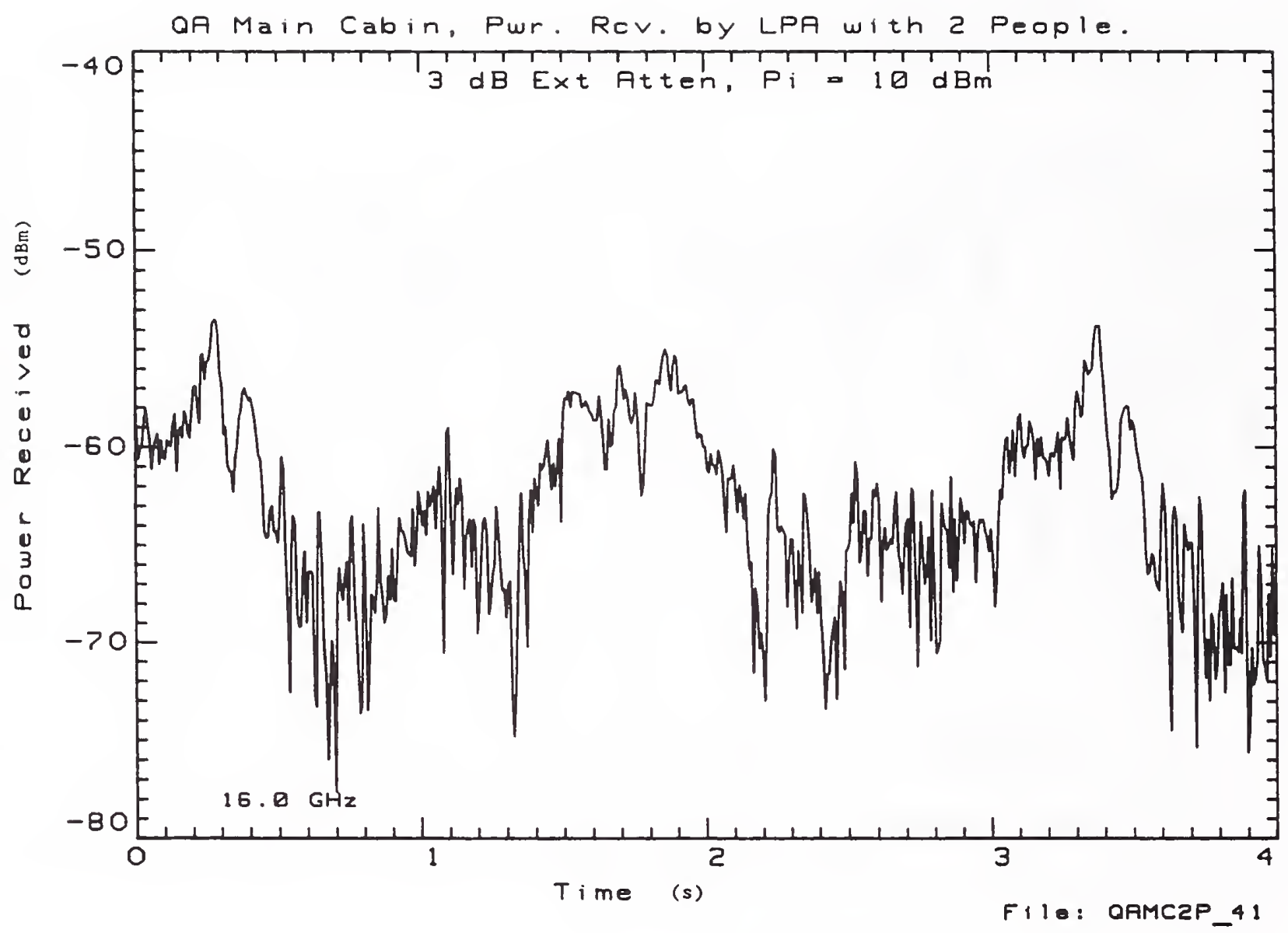

Figure 17. Received power versus time (stirrer position) in the main cabin of airplane 1 for two people. Frequency $=16.0 \mathrm{GHz}$. 


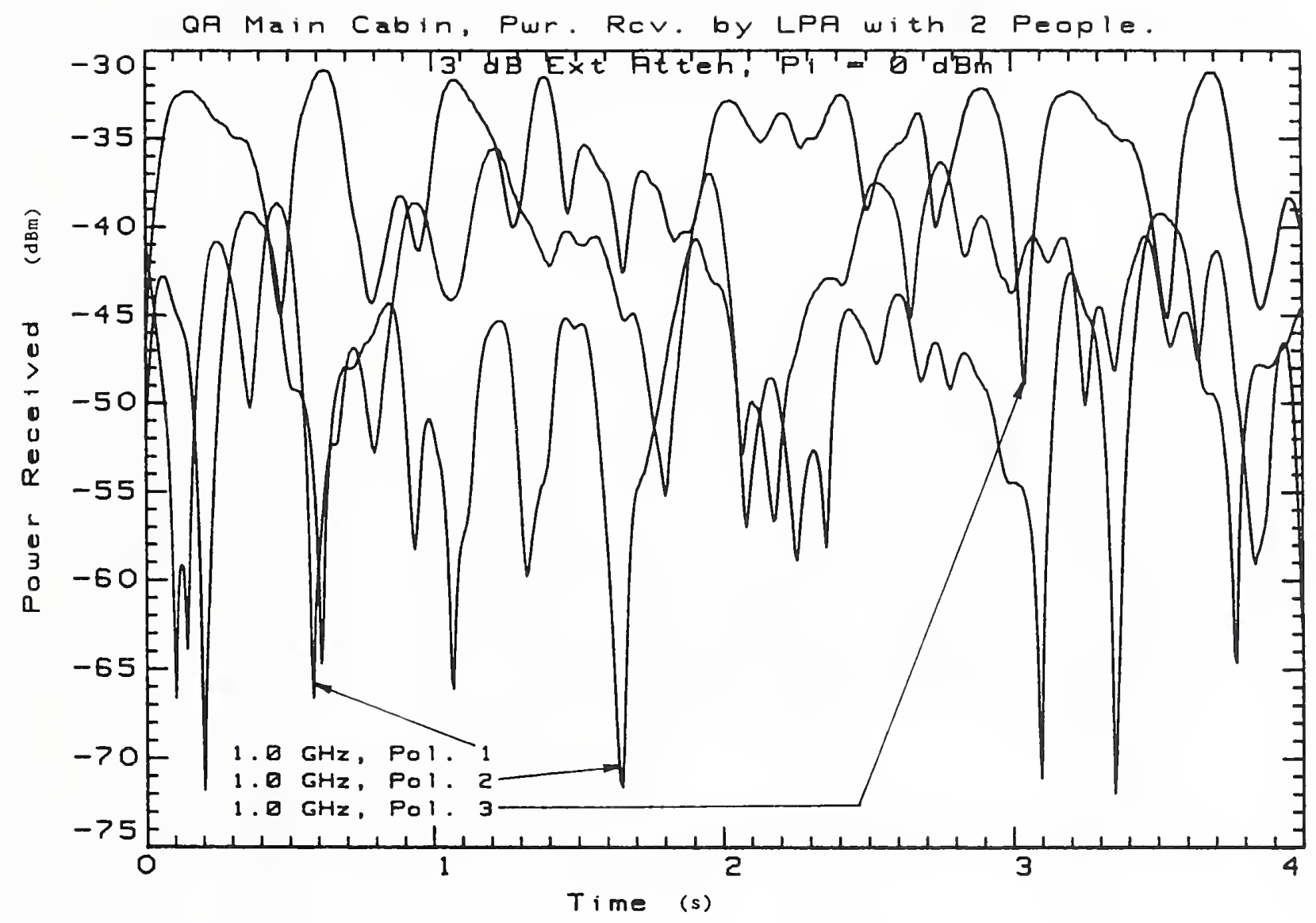

Figure 18. Received power versus time (stirrer position) in the main cabin of airplane 1 for two people for three antenna orientations. 


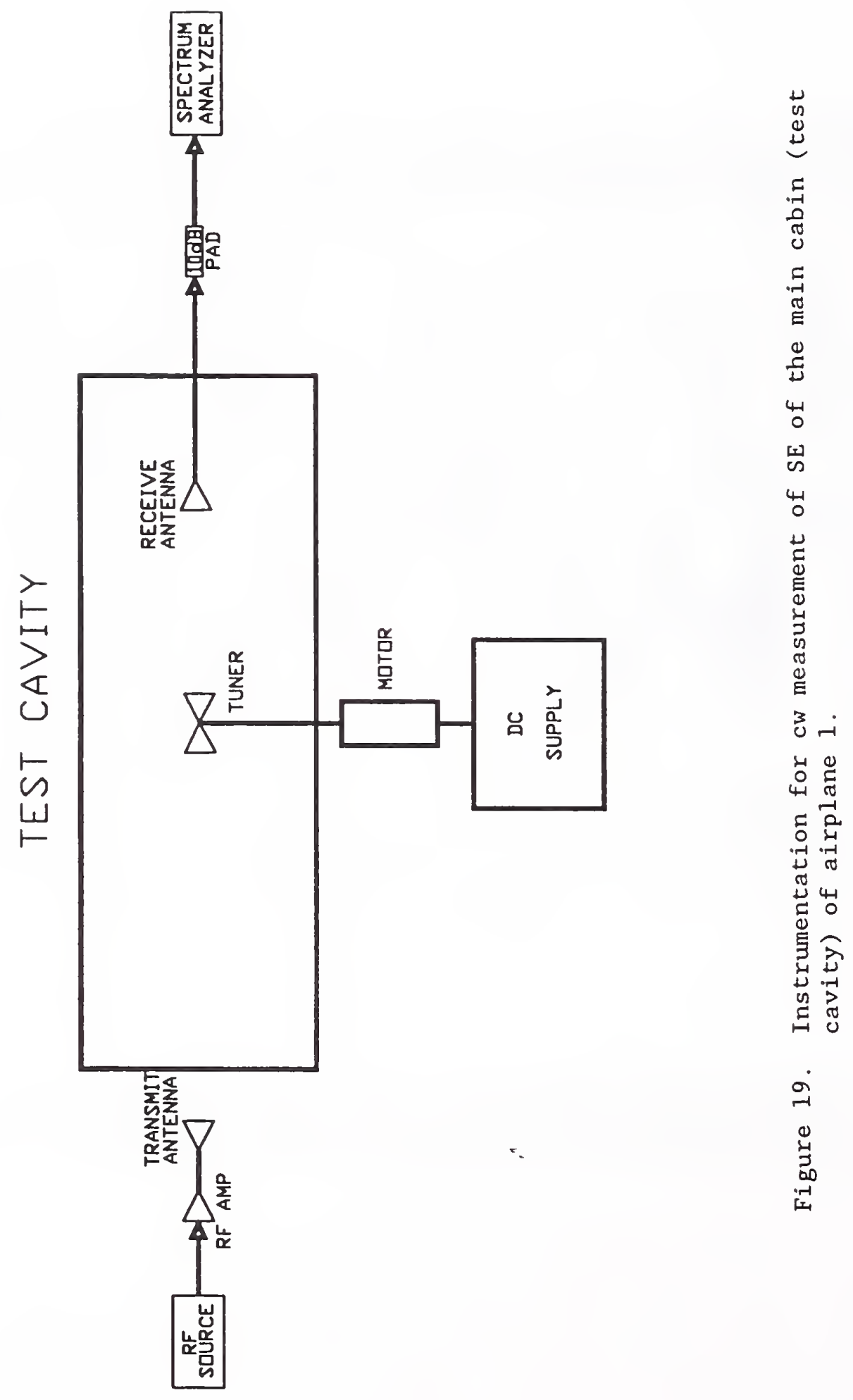




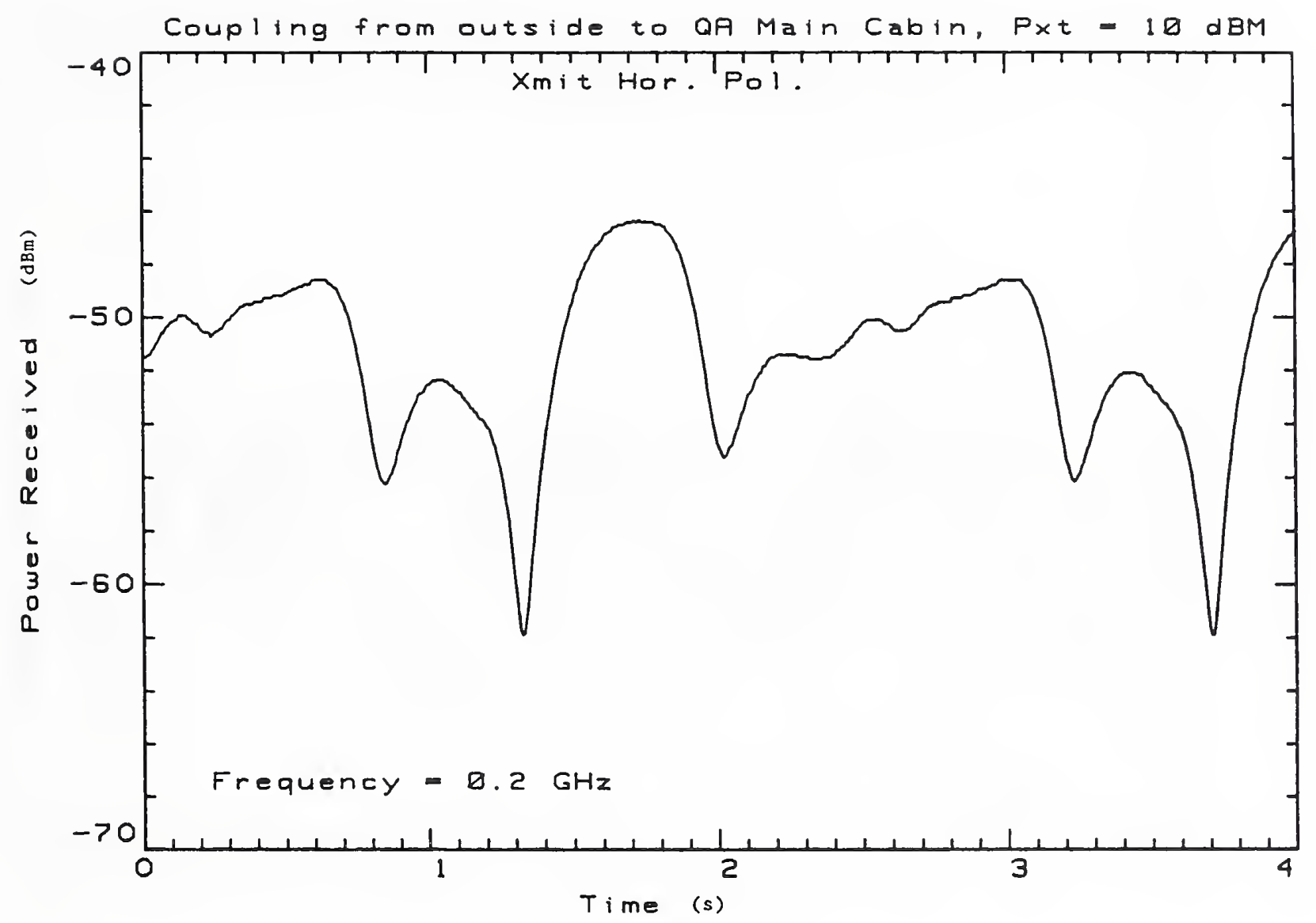

Figure 20. Received power versus time (stirrer position) in the main cabin of airplane 1 for an external source. Frequency $=0.2 \mathrm{GHz}$. 


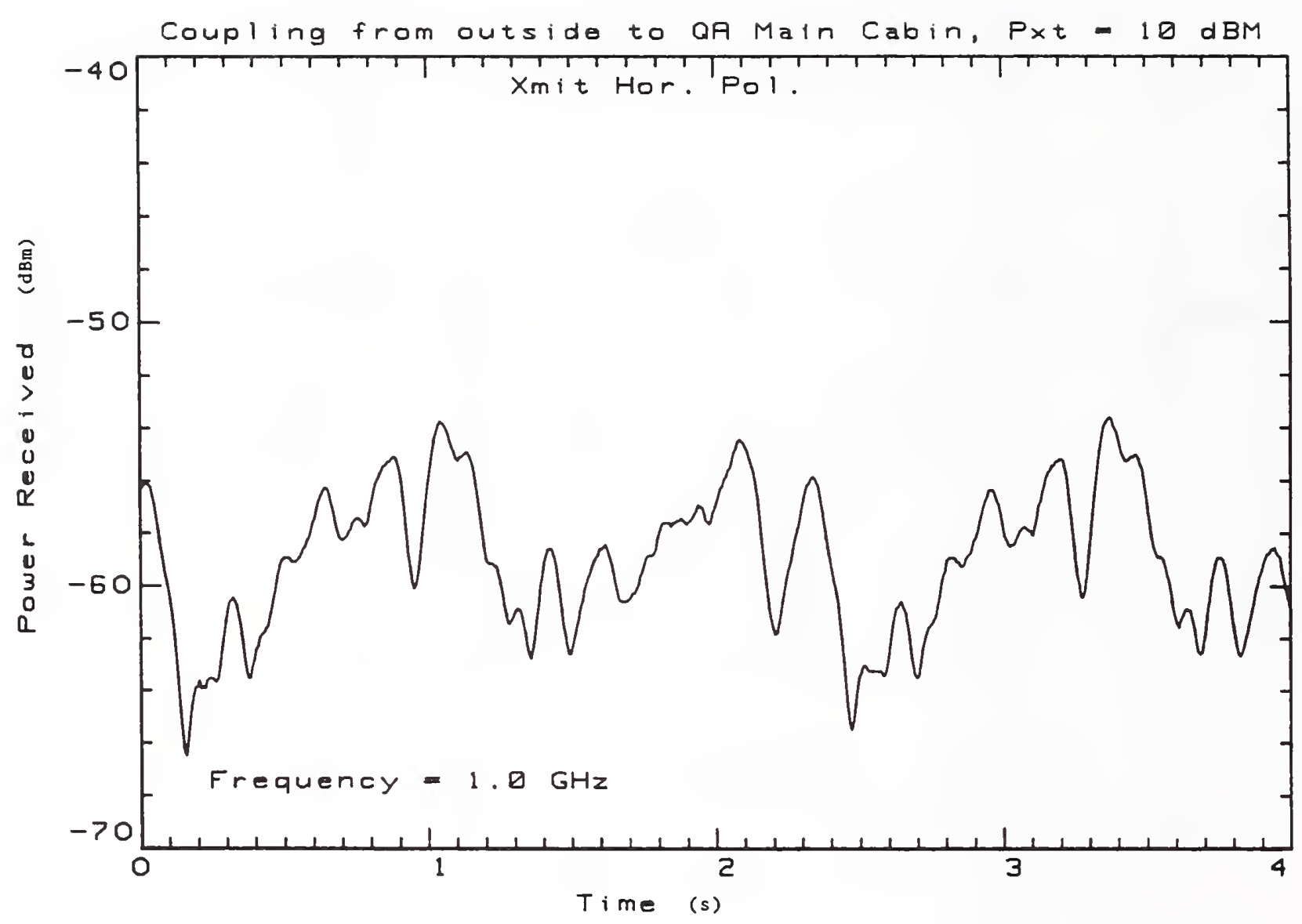

Figure 21. Received power versus time (stirrer position) in the main cabin of airplane 1 for an external source. Frequency $=1.0 \mathrm{GHz}$. 


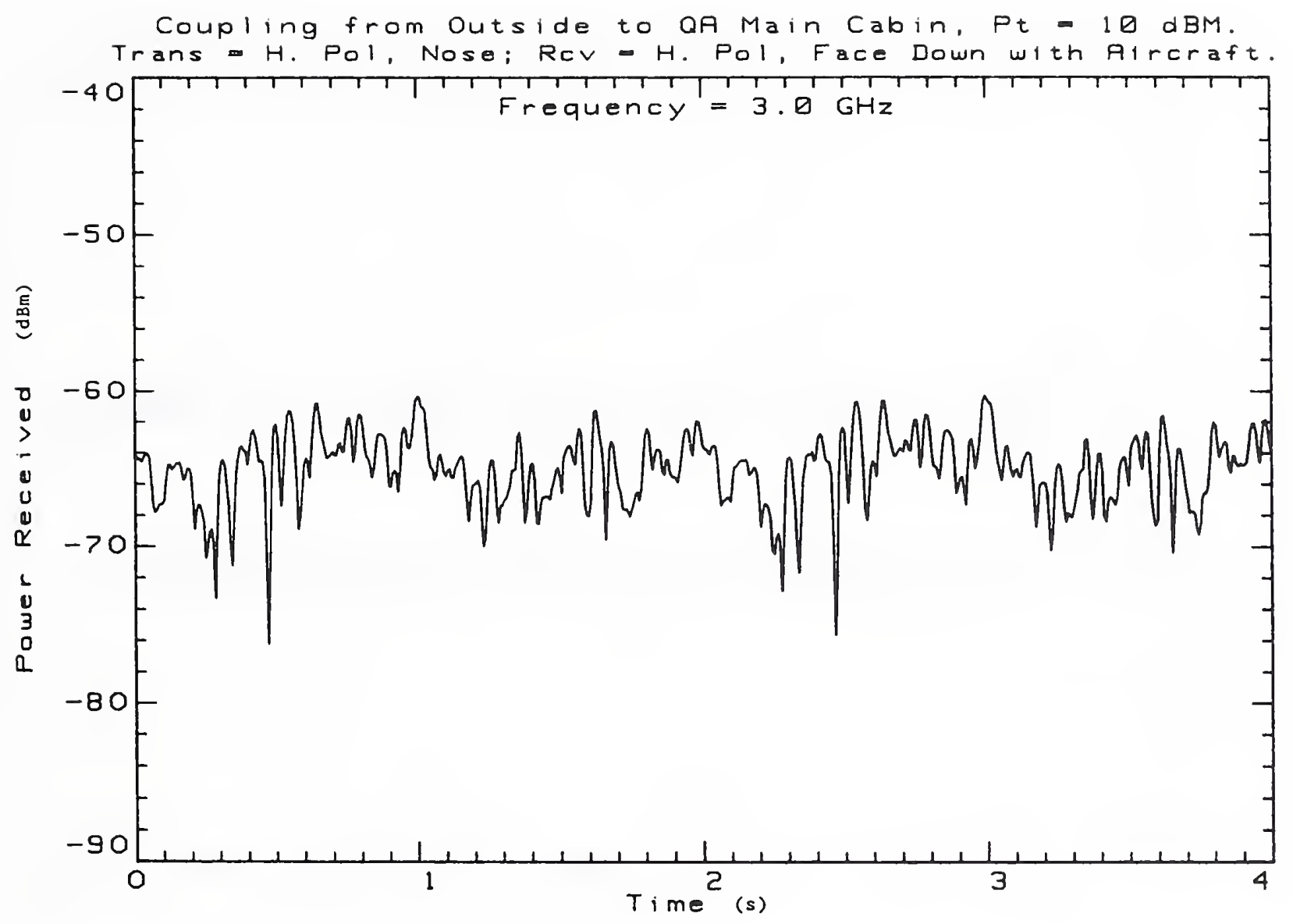

Figure 22. Received power versus time" (stirrer position) in the main cabin of airplane 1 for an external source. Frequency $=3.0 \mathrm{GHz}$. 


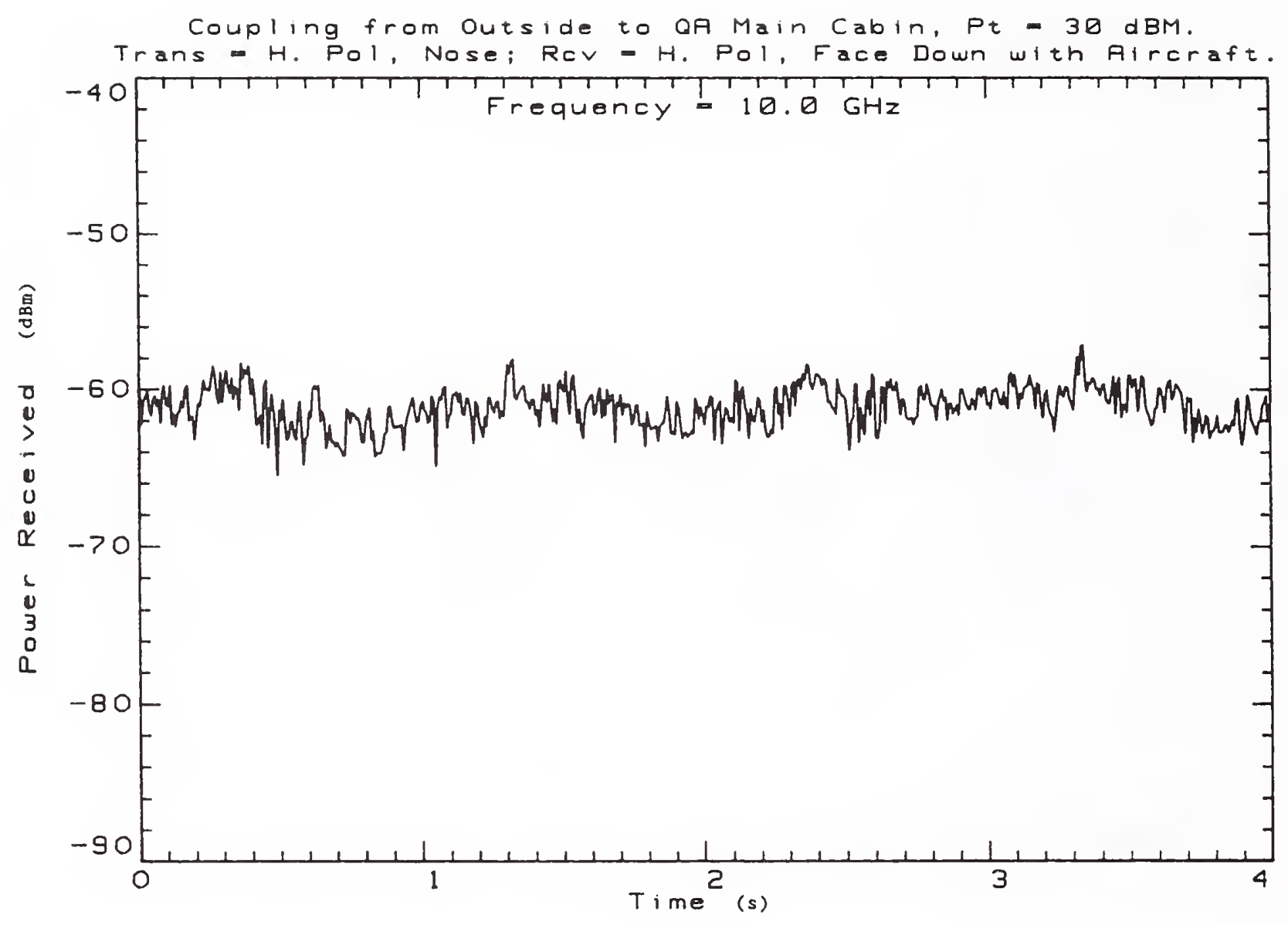

Figure 23. Received power versus time (stirrer position) in the main cabin of airplane 1 for an external source. Frequency $=10.0 \mathrm{GHz}$. 


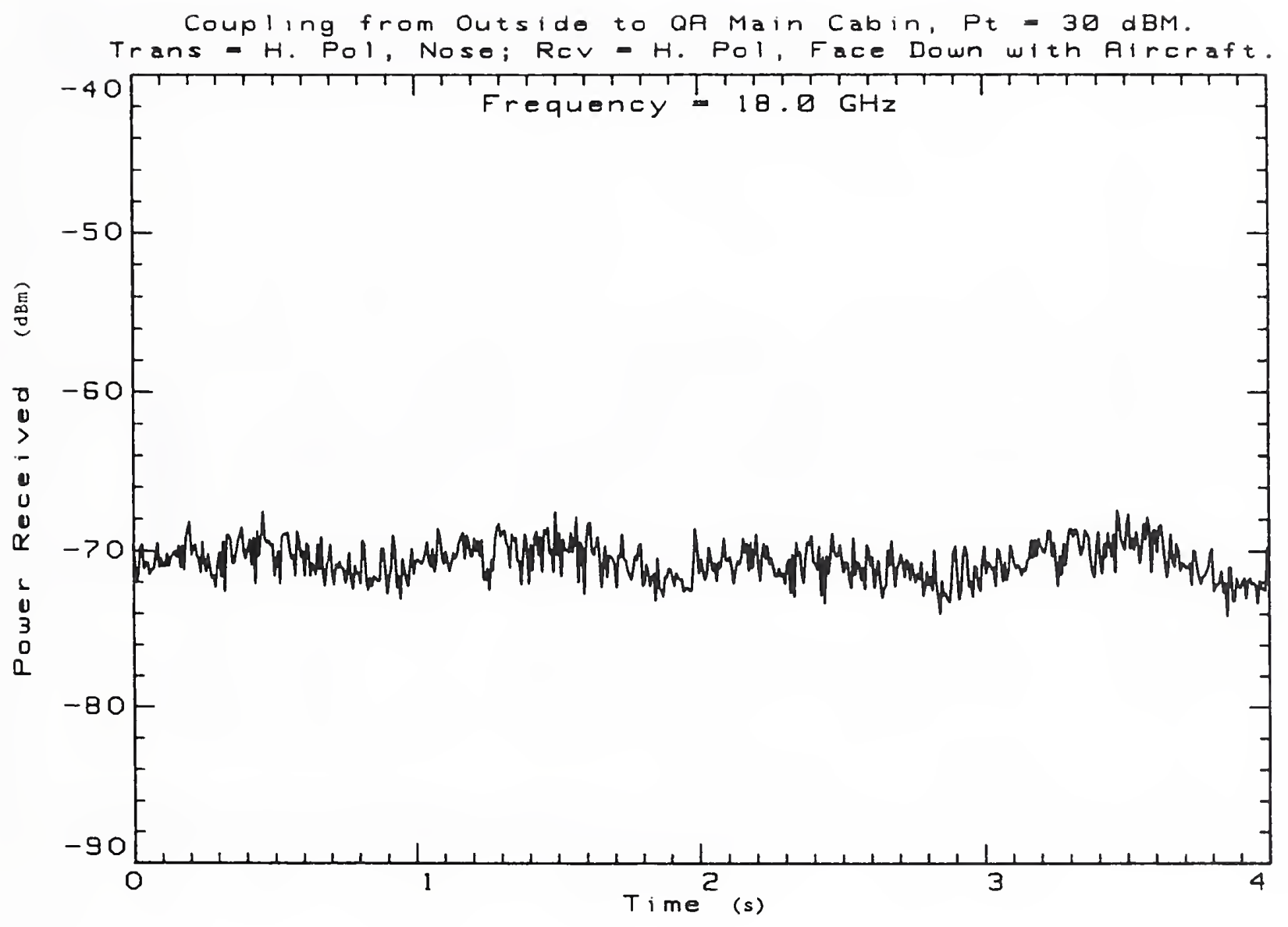

Figure 24. Received power versus time (stirrer position) in the main cabin of airplane 1 for an external source. Frequency $=18.0 \mathrm{GHz}$. 


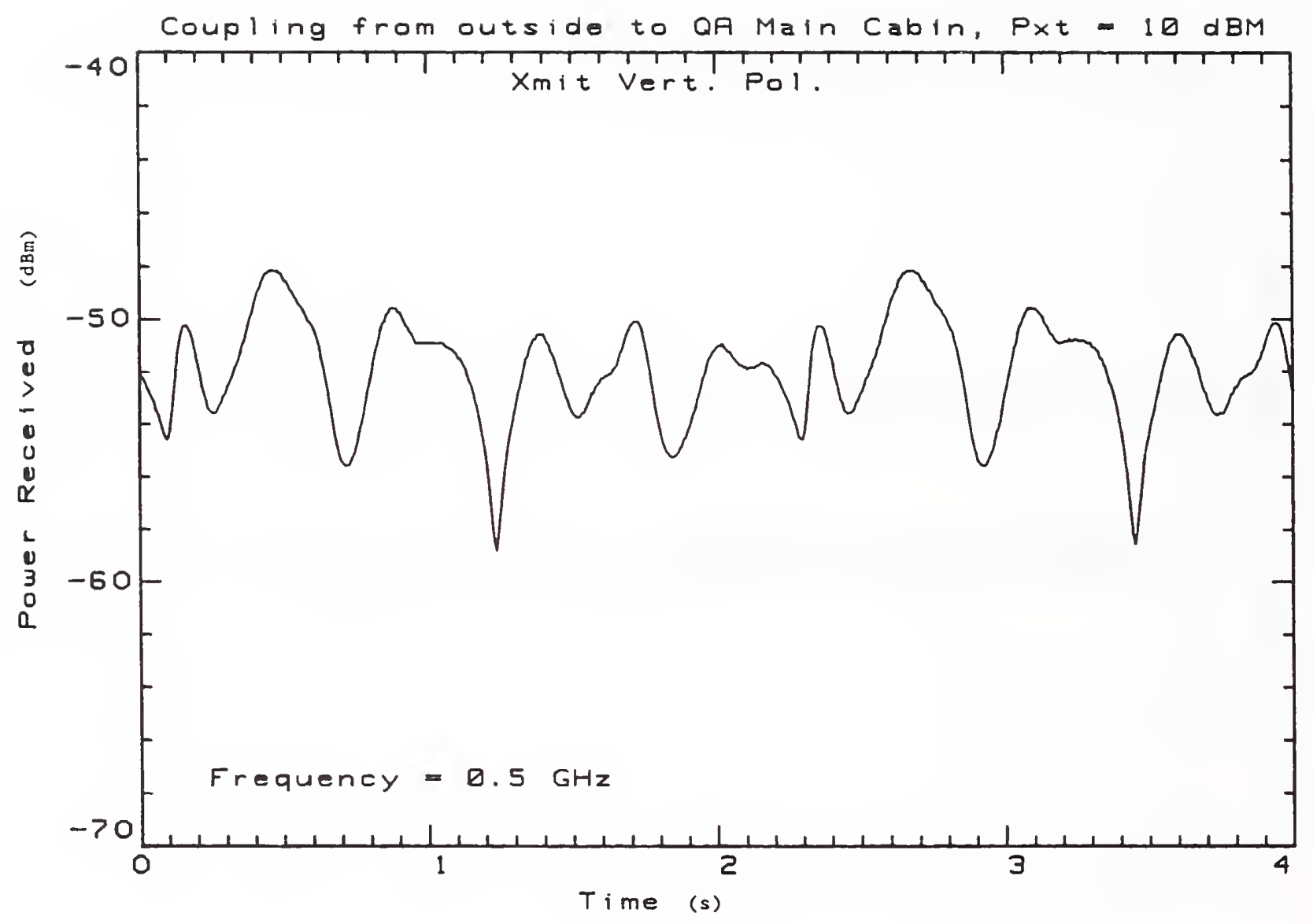

Figure 25. Received power versus time (stirrer position) in the main cabin of airplane 1 for a vertically polarized external source. Frequency $=18.0 \mathrm{GHz}$. 


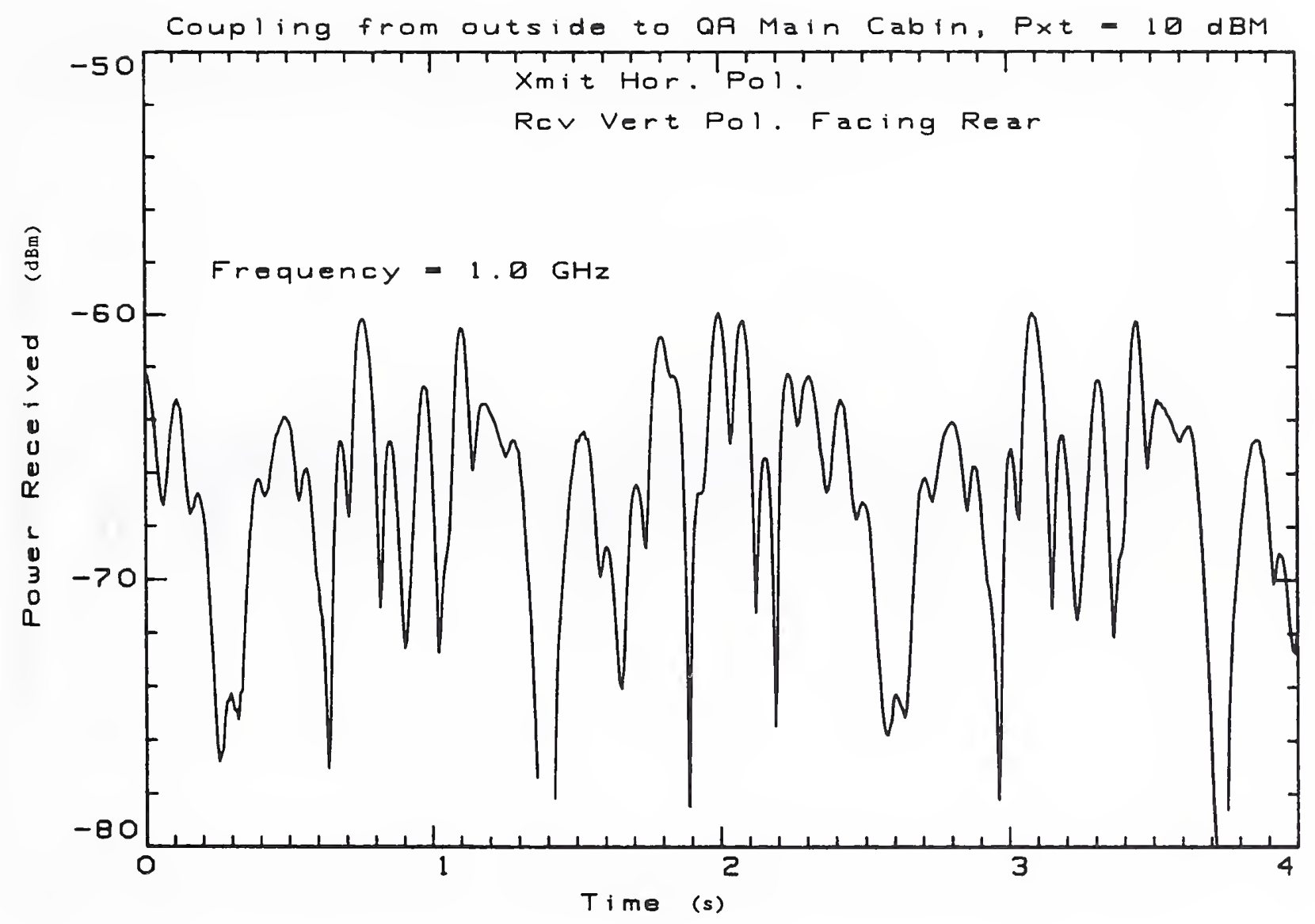

Figure 26. Received power versus time (stirrer position) in the main cabin of airplane 1 for a horizontally polarized external source and a vertically polarized receiving antenna. Frequency $=1.0 \mathrm{GHz}$. 


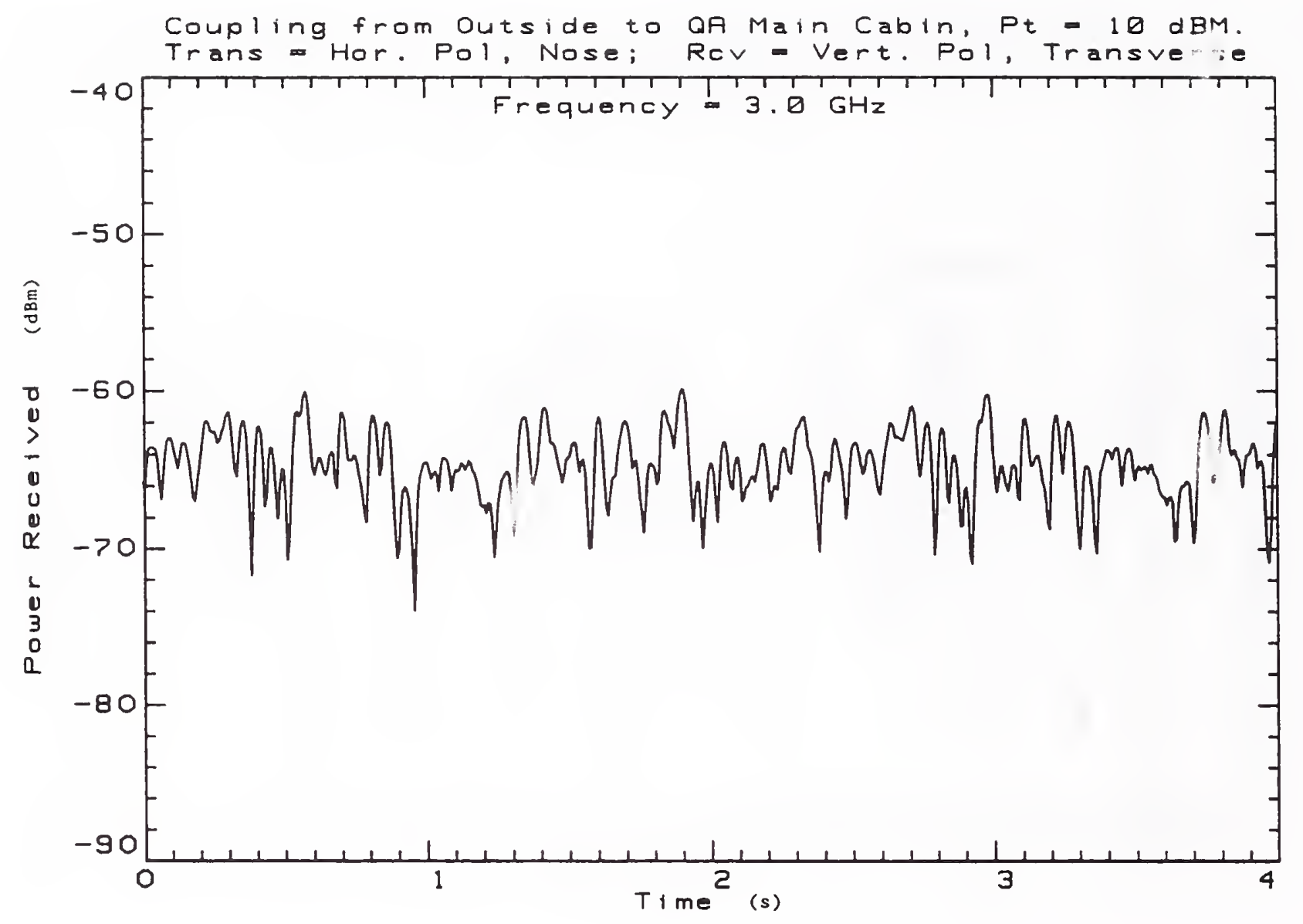

Figure 27. Received power versus time (stirrer position) in the main cabin of airplane 1 for a horizontally polarized external source and a vertically polarized receiving antenna. Frequency $=3.0 \mathrm{GHz}$. 


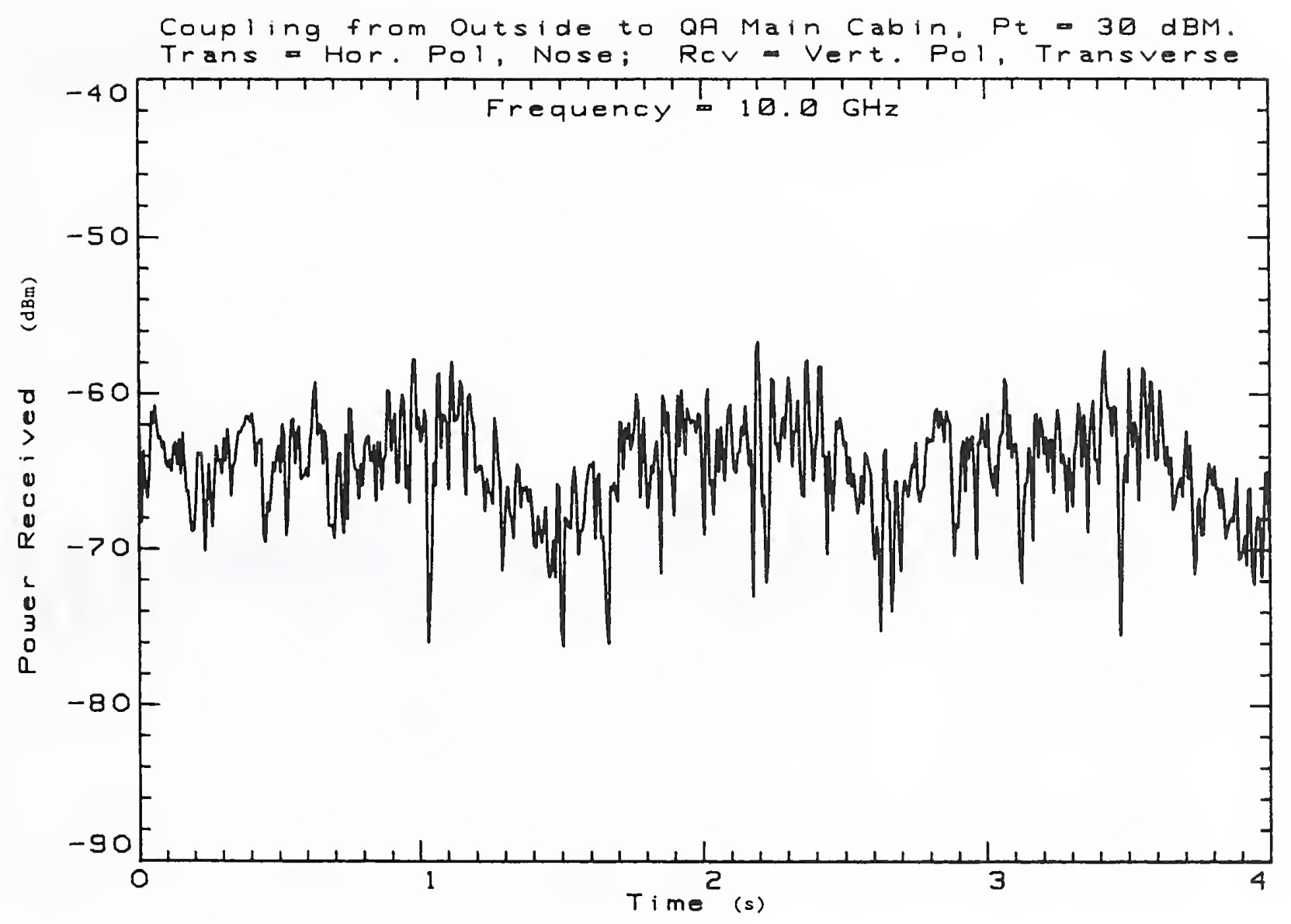

Figure 28. Received power versus time.(stirrer position) in the main cabin of airplane 1 for a horizontally polarized external source and a vertically polarized receiving antenna. Frequency $=10.0 \mathrm{GHz}$. 


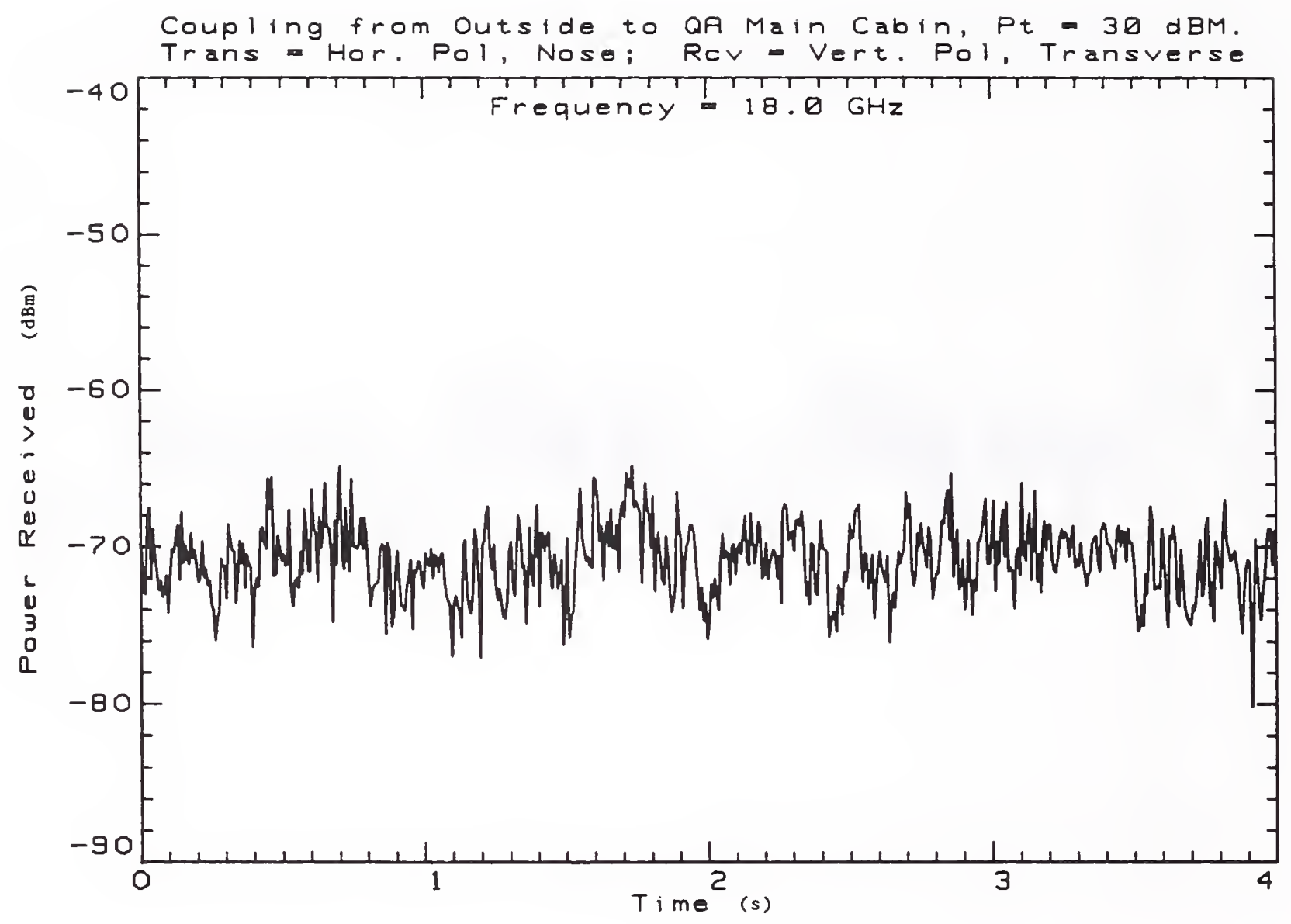

Figure 29. Received power versus time (stirrer position) in the main cabin of airplane 1 for a horizontally polarized external source and a vertically polarized receiving antenna. Frequency $=18.0 \mathrm{GHz}$. 


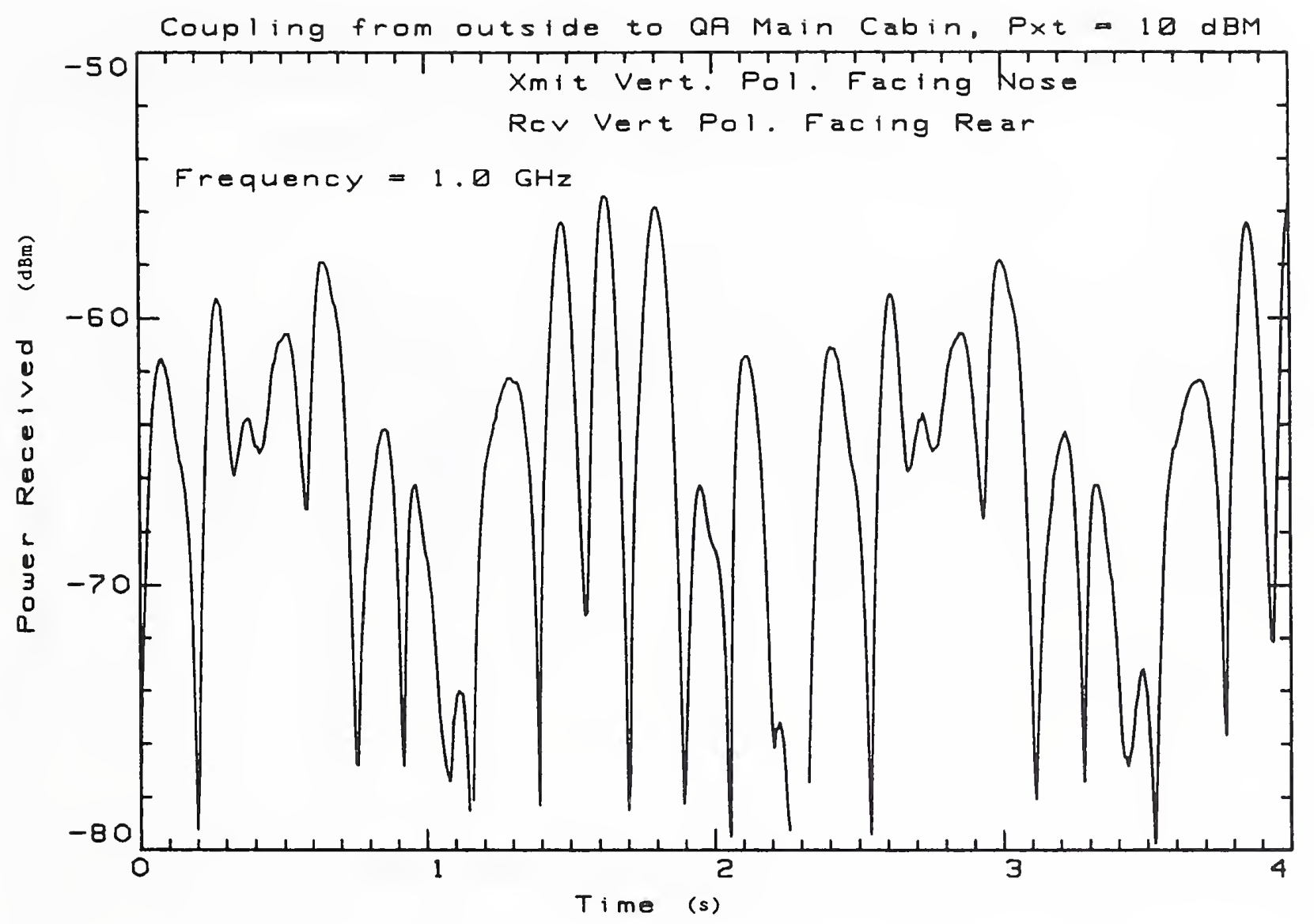

Figure 30. Received power versus time (stirrer position) in the main cabin of airplane 1 for a vertically polarized external source and a vertically polarized receiving antenna. Frequency $=1.0 \mathrm{GHz}$. 


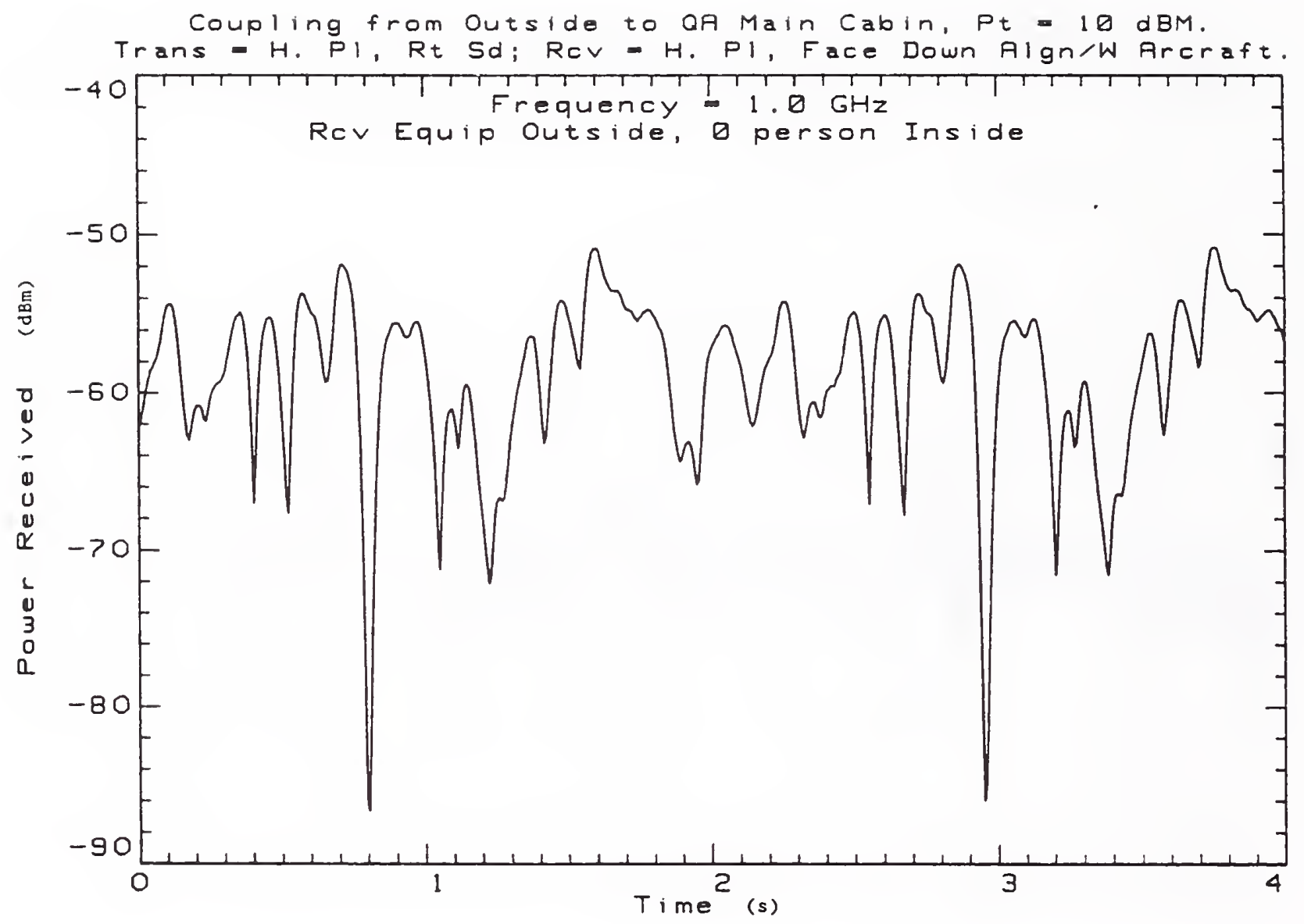

Figure 31. Received power versus time (stirrer position) in the main cabin of airplane 1 with no people inside for a vertically polarized external source and a vertically polarized receiving antenna. Frequency $=1.0 \mathrm{GHz}$. 


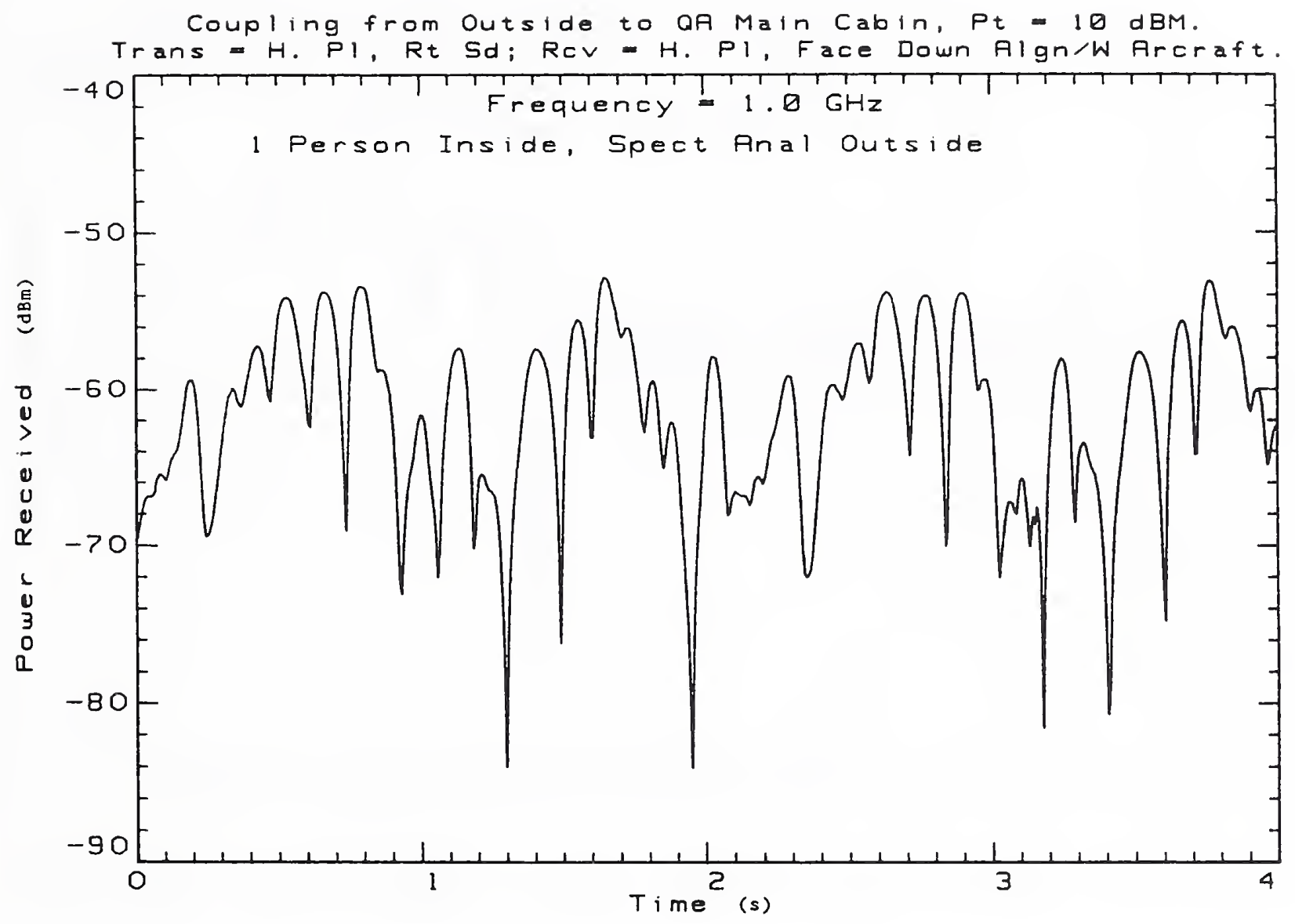

Figure 32. Received power versus time (stirrer position) in the main cabin of airplane 1 with one person inside for a vertically polarized external source and a vertically polarized receiving antenna. Frequency $=1.0 \mathrm{GHz}$. 


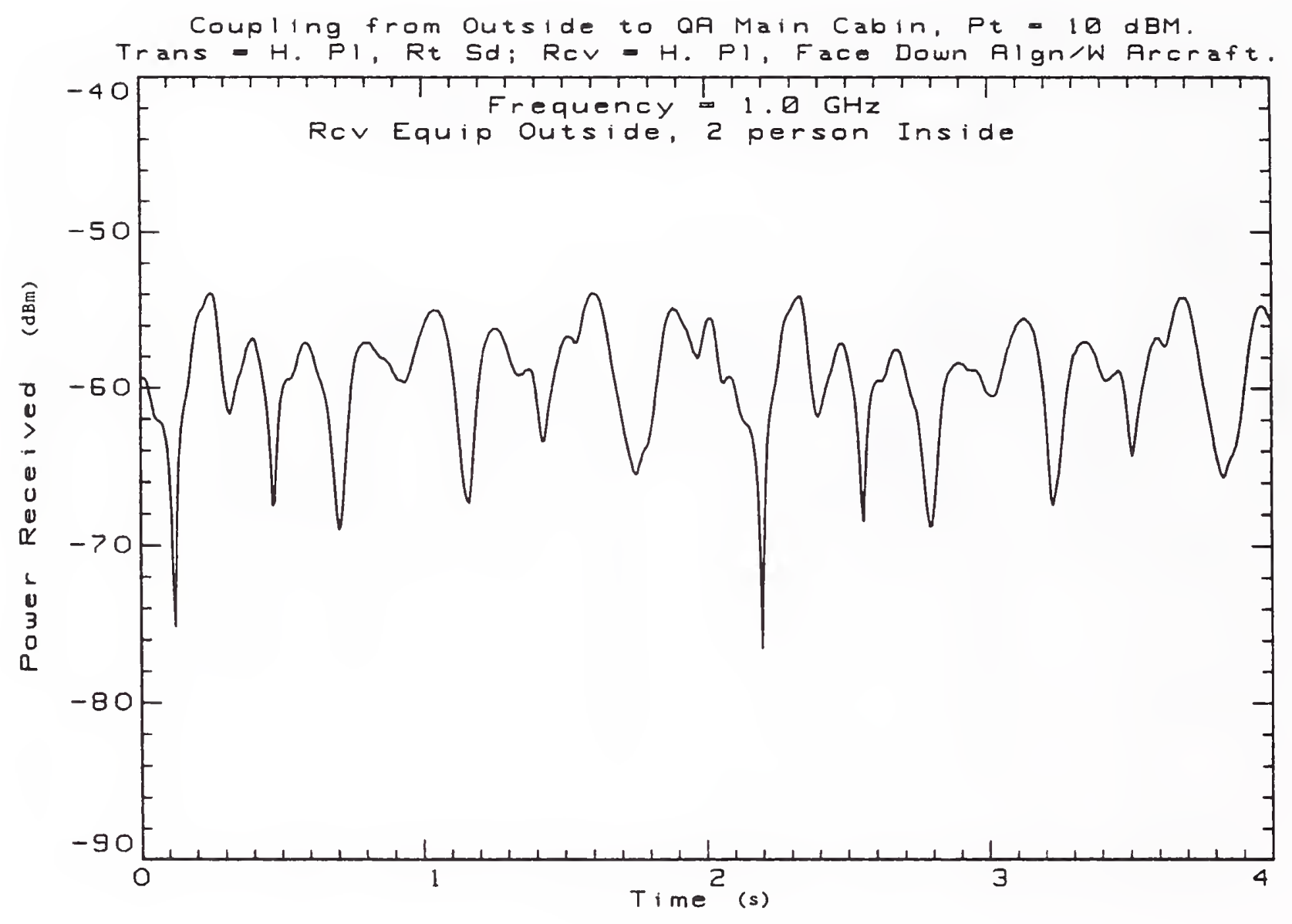

Figure 33. Received power versus time (stirrer position) in the main rabin of airplane 1 with two people inside for a vertically pol zed external source and a vertically polarized receiving anterina. Frequency $=1.0 \mathrm{GHz}$. 


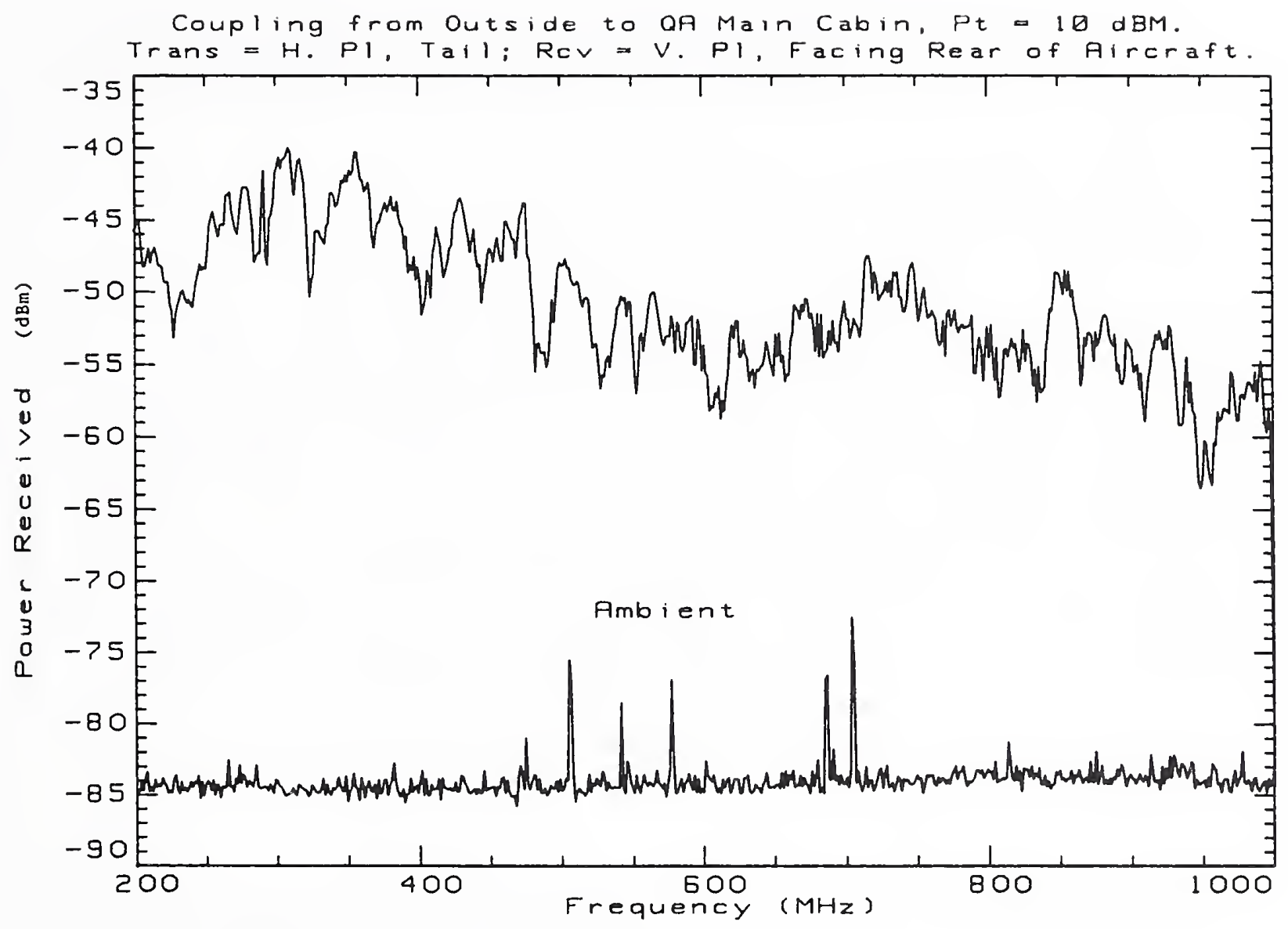

Figure 34. Power received in main cabin of airplane 1 from ambient field and external horizontally polarized source. 


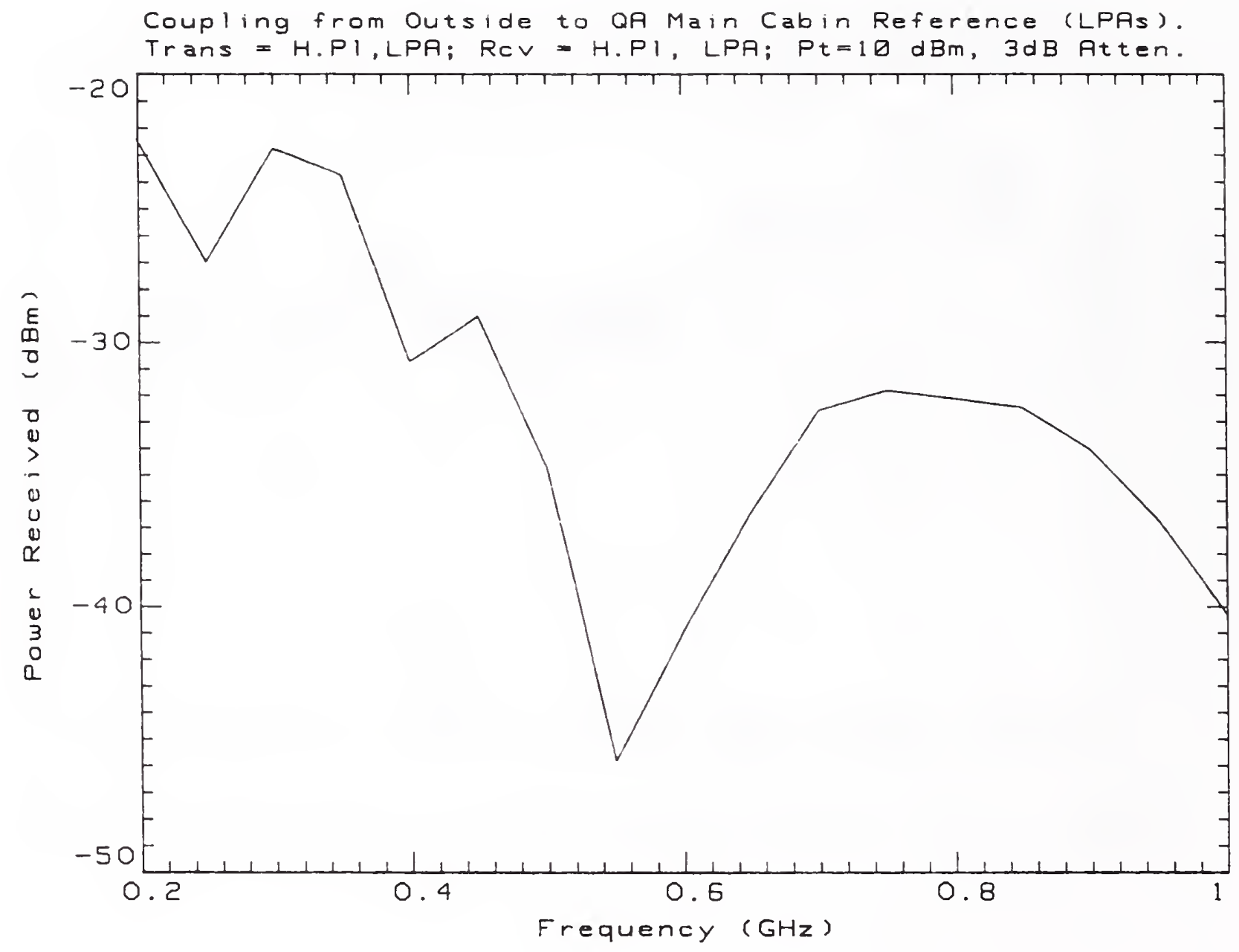

Figure 35. Reference power received for horizontally polarized transmitting and receiving $\log$ periodic dipoles at frequencies below $1 \mathrm{GHz}$. 


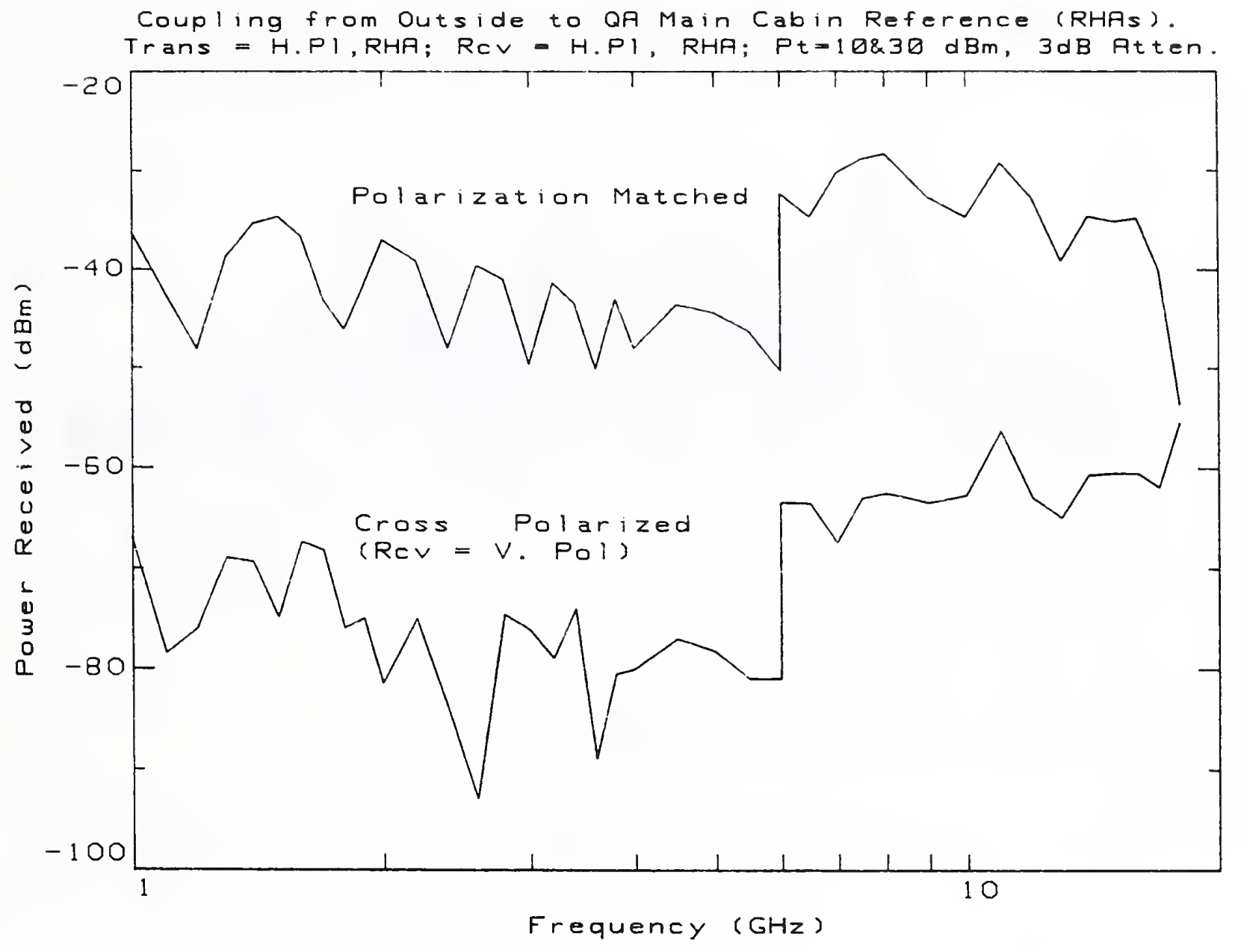

Figure 36. Reference power received for a horizontally polarized transmitting ridged horn antenna at frequencies above $1 \mathrm{GHz}$. 


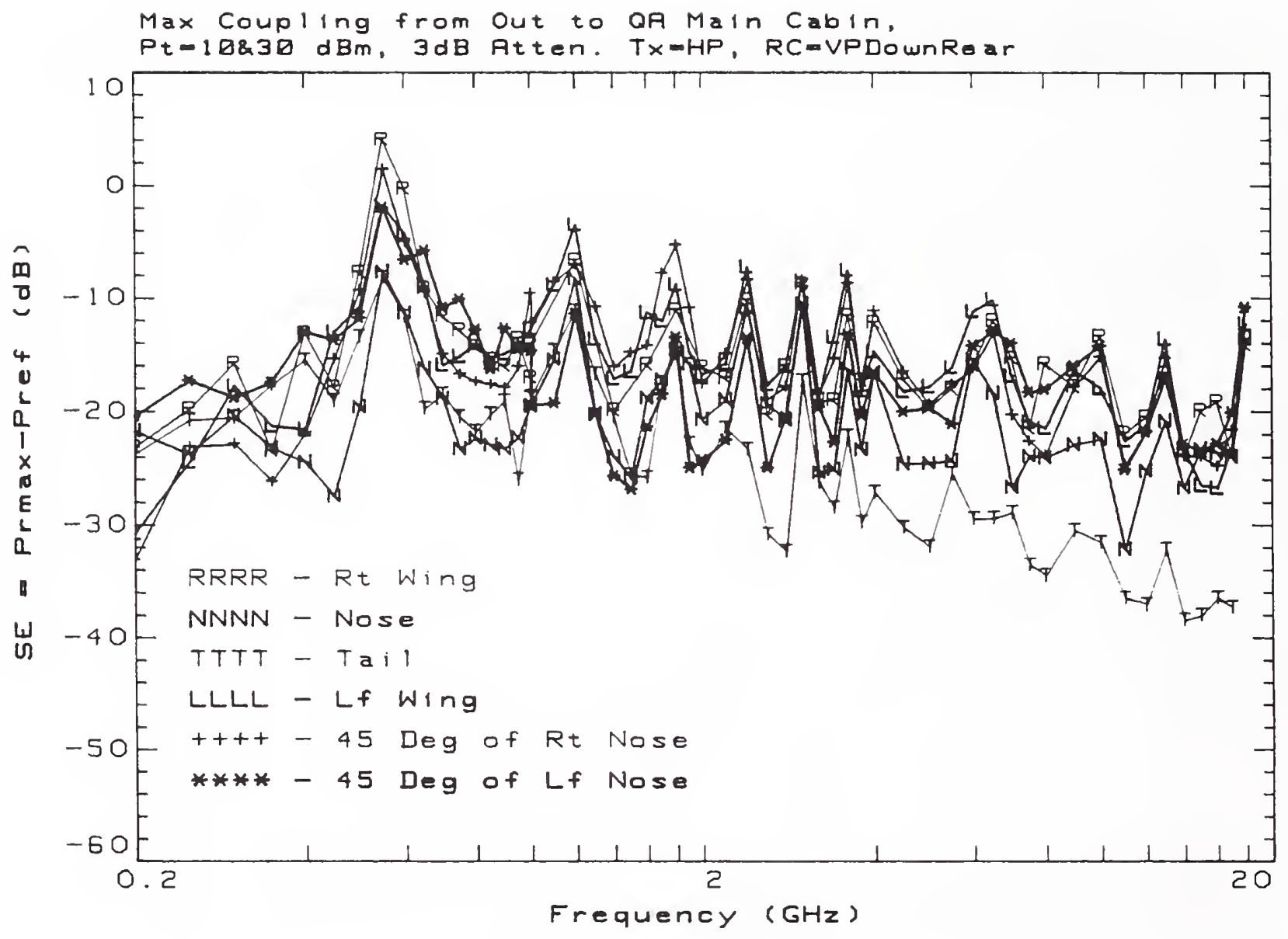

Figure 37. Shielding effectiveness of the main cabin of airplane 1 for six different incidence directions. 


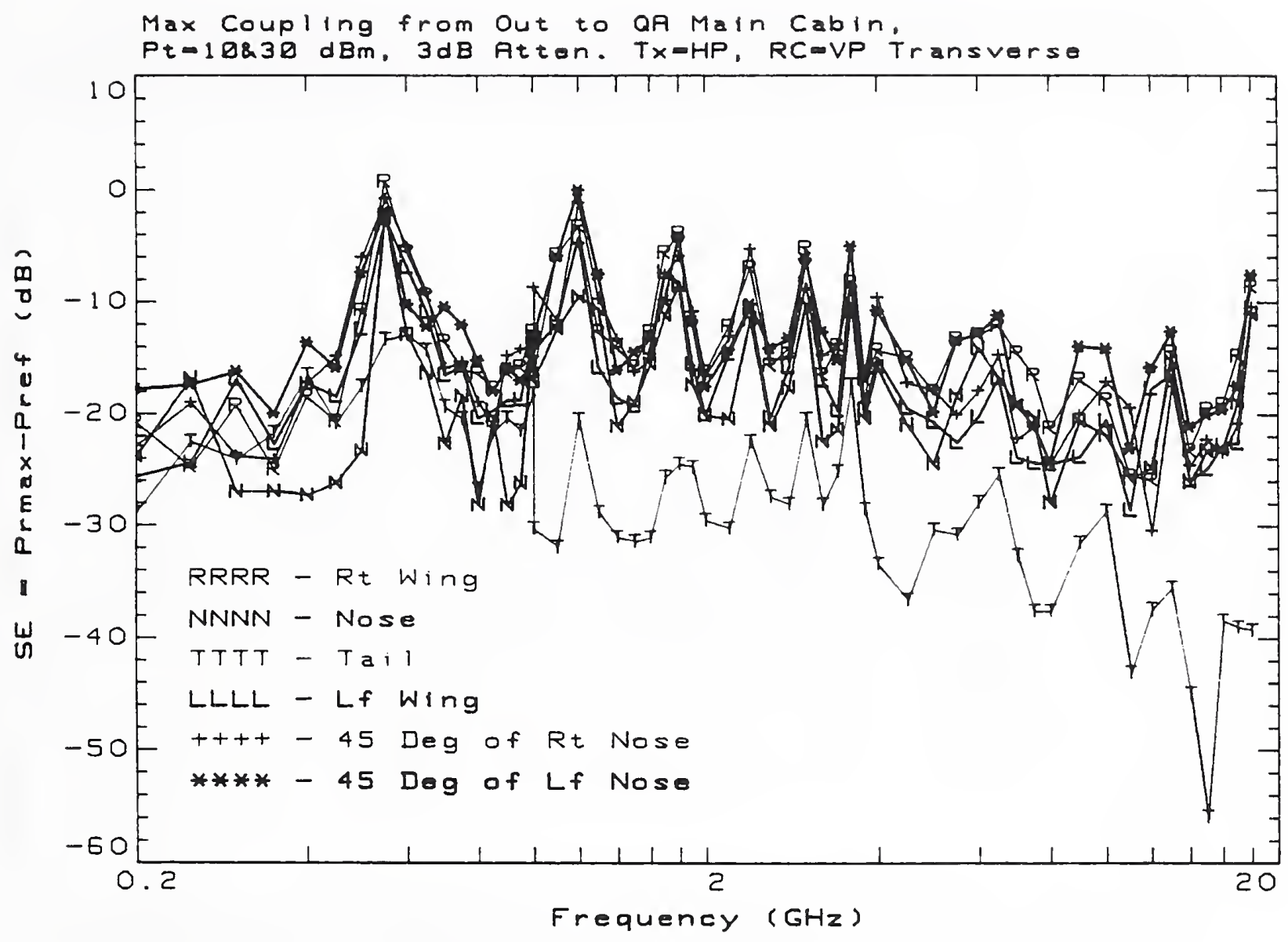

Figure 38. Shielding effectiveness of the main cabin of airplane 1 for six different incidence directions and a different (transverse) orientation of the receiving antenna. 


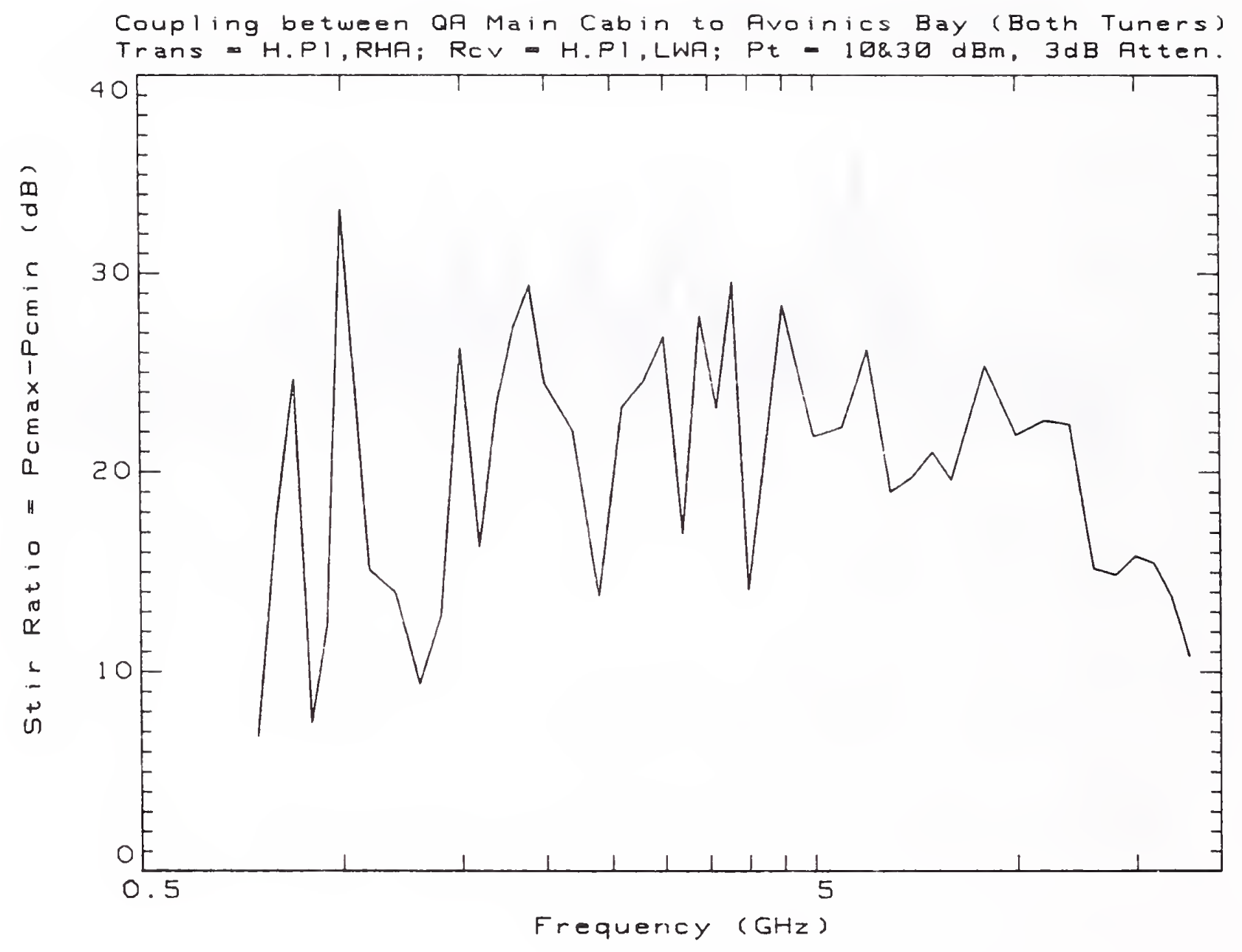

Figure 39. Stir ratio (maximum/minimum) for a transmitting antenna in the main cabin and a receiving antenna in the avionics ay of airplane 1 . 
Coupling between OA Main Cabin to Avoinics Bay (Both Tuners) Trans = H.PI, RHA; Rev = H.PI, LWA; Pt = 10830 dBm, 3dB Atten.

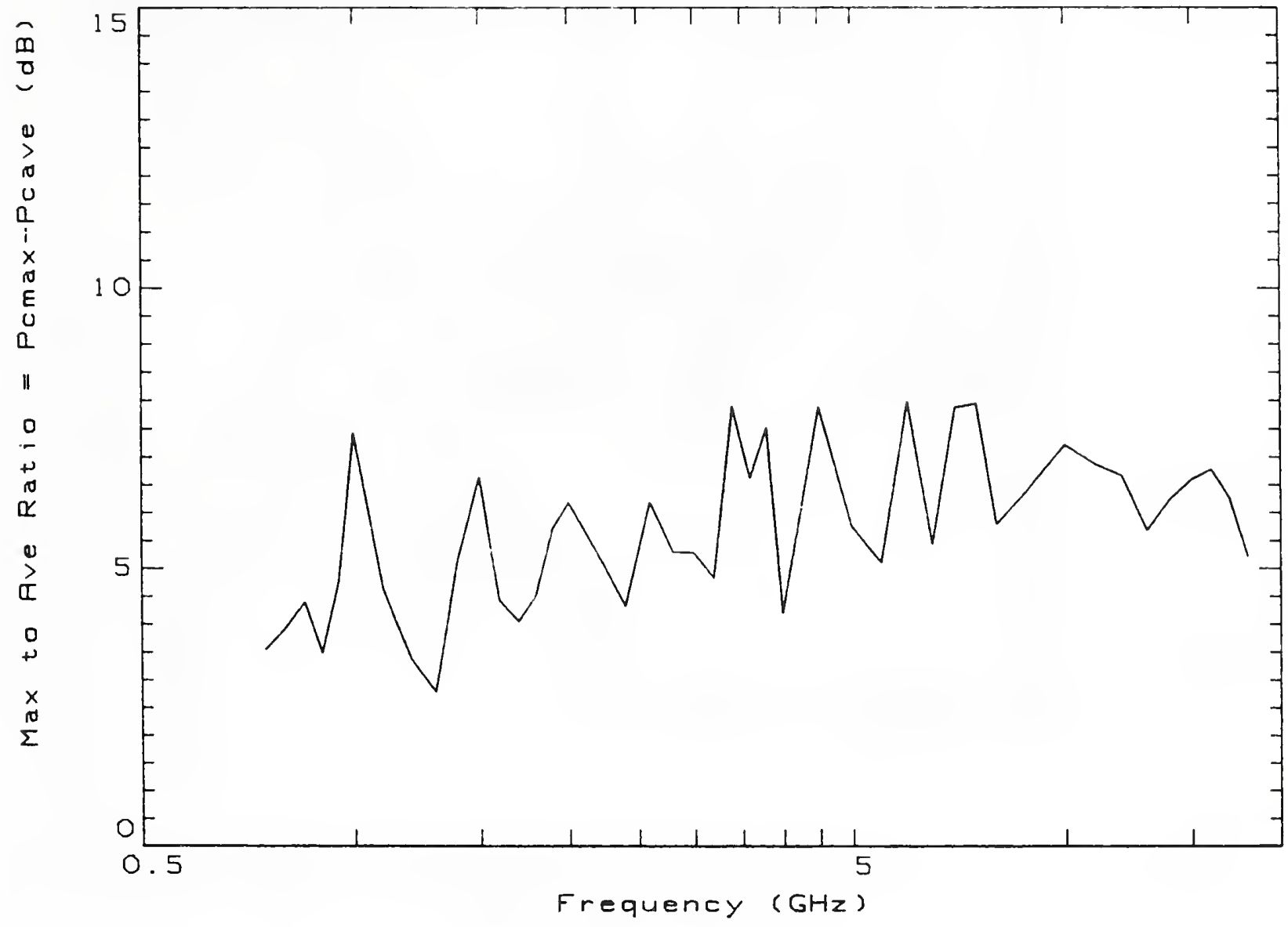

Figure 40. Difference between maximüm and average received power for a transmitting antenna in the main cabin and a receiving antenna in the avionics bay of airplane 1 . 


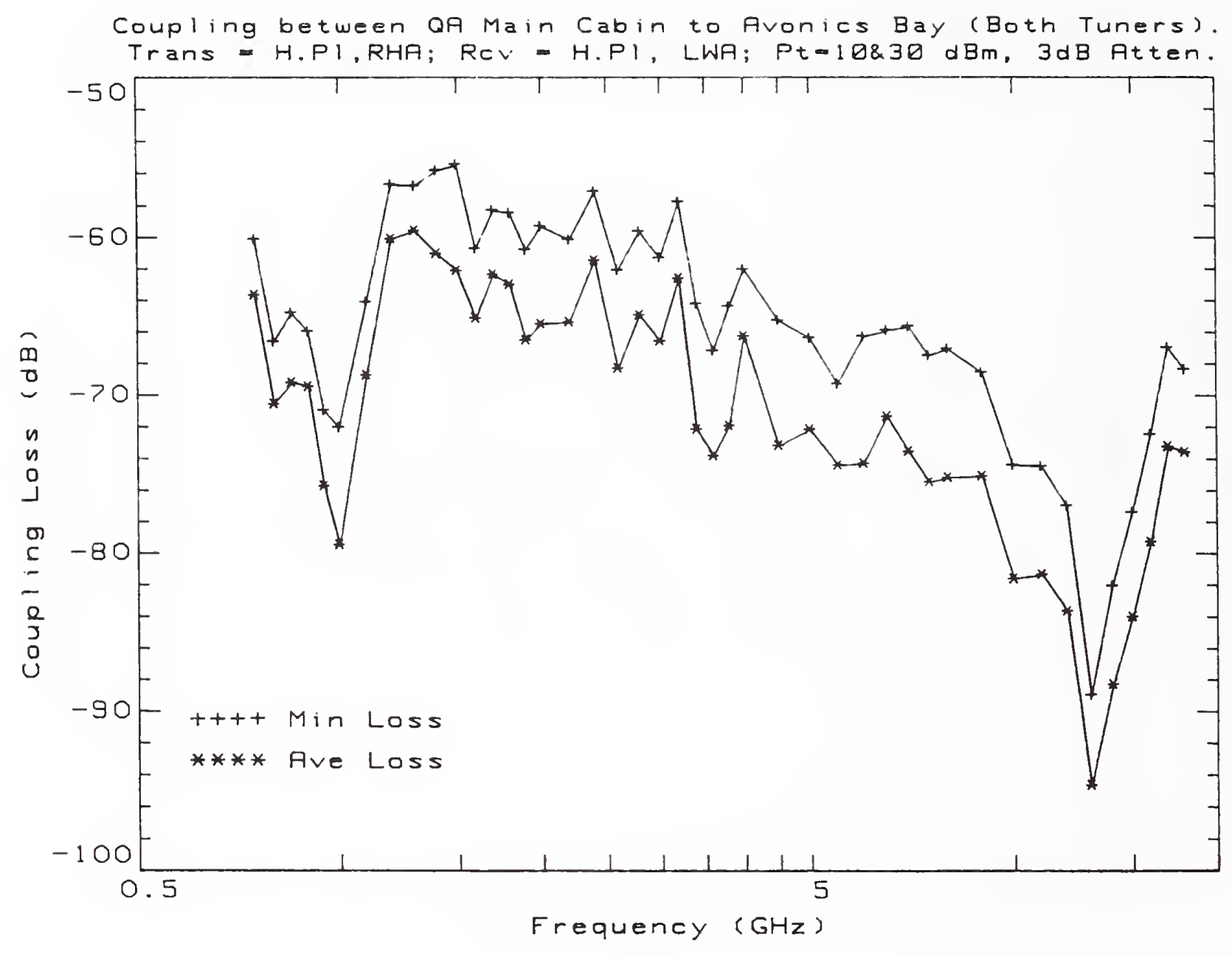

Figure 41. Average and minimum coupling loss between the main cabin and avionics bay of airplane 1 . 


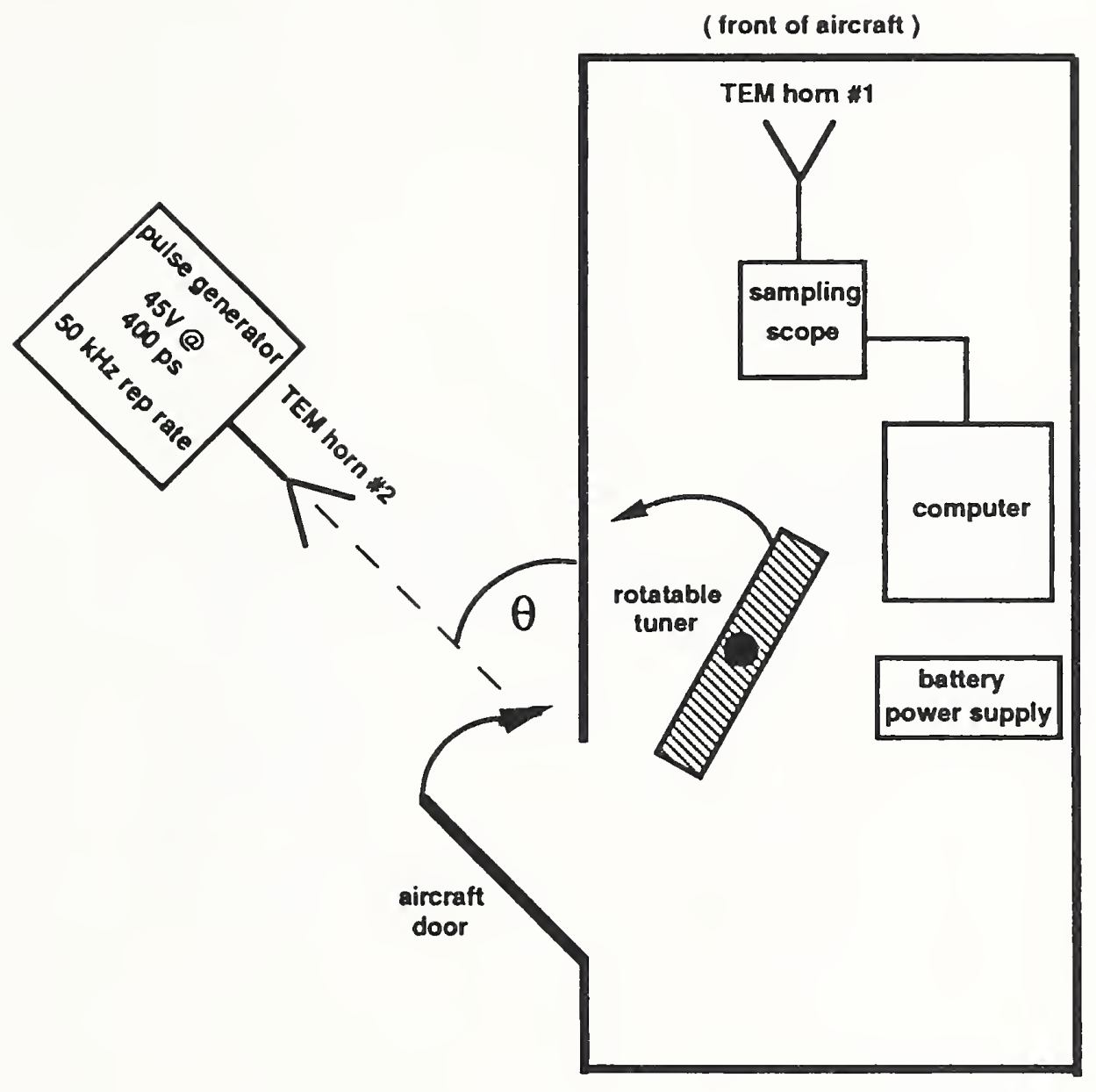

Figure 42. Instrumentation for the time-domain measurement of SE of the main cabin of airplane 2 . 

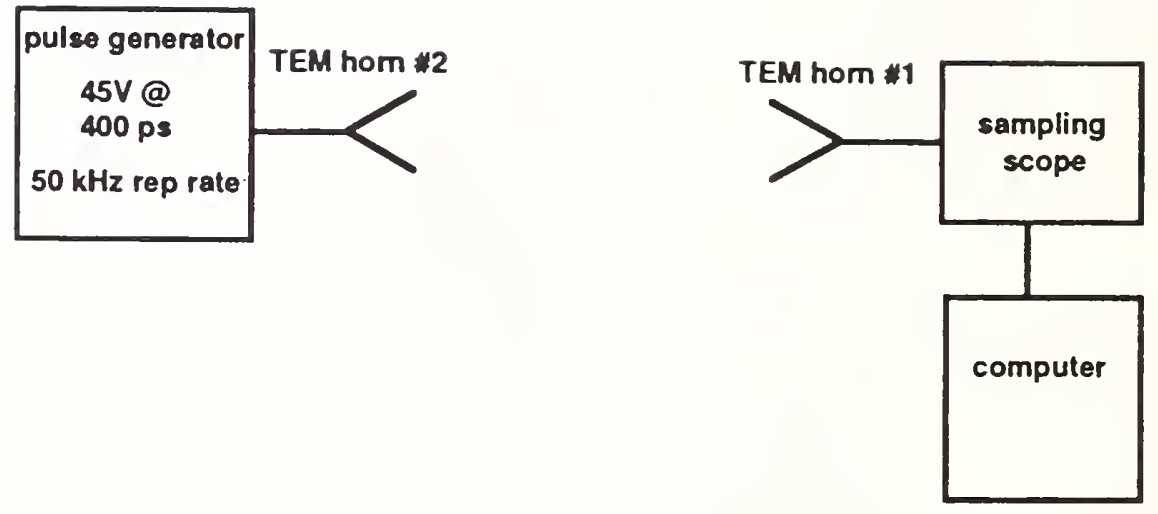

Figure 43. Instrumentation for the time-domain measurement of the reference field illumination. 

